\title{
Identificação, mensuração e caracterização das perdas por transporte em processos construtivos
}

\author{
Identification, measurement and characterization of \\ transport waste on construction processes
}

\section{Cristina Toca Pérez \\ Dayana Bastos Costa Jardel Pereira Gonçalves}

Resumo foi Design Science Research, desenvolvida a partir de dois estudos de caso em processos ainda poucos empregados no Brasil, quais sejam, revestimento com argamassa projetada e Light Steel Frame. Esses estudos foram conduzidos a partir das etapas de identificação dos fluxos físicos, identificação da distribuição dos tempos dos trabalhadores e caracterização das perdas por transporte. Múltiplas fontes de evidências, ferramentas e técnicas foram utilizadas para a organização dos eventos de perda por transporte, associados a suas causas e consequências. Os resultados obtidos indicaram que a maior parte das perdas por transporte foram ocasionadas por problemas de mobilidade dentro do canteiro. Problemas causados pela falta de equipamentos apropriados foram os que mais perda de tempo ocasionaram. A redução das condições de segurança e a necessidade de um novo transporte foram as principais consequências observadas. As principais contribuições deste estudo estão relacionadas ao maior entendimento da natureza das perdas por transporte, à adoção de ferramentas e indicadores para a caracterização das perdas por transporte do ponto de vista de sua incidência e tempos, bem como uma proposta de classificação das principais causas e consequências para a caracterização dessas perdas.

Palavras-chaves: Construção enxuta. Perdas na construção. Perdas por transporte.
Cristina Toca Pérez Universidade Federal da Bahia Salvador - BA - Brasil

Dayana Bastos Costa Universidade Federal da Bahia Salvador - BA - Brasil

Jardel Pereira Gonçalves Universidade Federal da Bahia Salvador - BA - Brasil

Recebido em 03/03/15 Aceito em 18/09/15

\begin{abstract}
This paper aims to present the process of identification, measurement and characterization of transport wastes in construction processes, taking into consideration their incidence, times, causes and consequences. The method adopted was Design Science Research, carried out through two case studies in processes that are still sparsely used in Brazil, i.e., the projected mortar coating system and the Light Steel Frame technology. The studies were conducted through the following steps: identification of physical flows, identification of the distribution of workforce production time, and identification and quantification of transport wastes' causes. Multiples sources of evidence, tools and techniques were used for the data collection in order to describe each transportation waste event, asociated on its cause and impacts. The findings indicated that most of the transport waste events were caused by problems related to access and mobility on the jobsite, however, the problems caused by lack of appropriate equipment to carry out the transport activities were the most common cause of lost time. Unsafe conditions and new transport were the principal consequences observed. The main contributions of this study are related to an improved understanding of the nature of the transportation wastes, as well as the definition of a set of tools and indicators to characterize transport waste, and a proposal of classification of transport waste causes and consequences to characterize these wastes.
\end{abstract}

Keywords: Lean construction. Construction waste. Transport wastes. 


\section{Introdução}

O conceito de perdas na produção vem sendo adotado desde o início do século XX (KOSKELA; SACKS; ROOKE, 2012). Para Ohno (1988), perda é qualquer atividade humana que absorve recursos, mas não cria valor, tais como erros que requerem retificação, produção de itens que ninguém quer, estoques ou transporte de bens. Isso significa que as perdas englobam tanto a ocorrência de desperdícios de materiais quanto a execução de tarefas desnecessárias, que geram custos adicionais e que não agregam valor (FORMOSO et al., 1996).

Visando tornar explícitos os diferentes tipos de perdas, Ohno (1988) enumerou as seguintes perdas comumente encontradas na produção: por superprodução, por transporte, por processamento em si, por fabricação de produtos defeituosos, no movimento, por espera e por estoque. Essa classificação tem sido amplamente usada pelos seguidores do Sistema Toyota de Produção (STP) e da Produção Enxuta (Lean Production), e vem sendo adaptada e difundida em diferentes indústrias, inclusive na construção civil (KOSKELA; BØLVIKEN; ROOKE, 2013).

Especificamente na construção civil, existe um esforço no meio acadêmico para compreender melhor as perdas. Formoso et al. (2002), Macomber e Howell (2004) e Koskela (2004) defendem que a classificação proposta por Ohno (1988) não é completa para a construção civil, sendo necessárias novas subdivisões e definições mais contextualizadas ao setor. Mais recentemente diversos trabalhos foram apresentados sobre $o$ tema nas conferências do International Group for Lean Construction (IGLC) ${ }^{1}$ (VIANA; FORMOSO; KALSAAS, 2012; KOSKELA; SACKS; ROOKE, 2012; KALSAAS, 2013; BØLVIKEN; ROOKE; KOSKELA, 2014; FORMOSO et al., 2015). Especificamente, Bølviken, Rooke e Koskela (2014) apresentaram uma proposta de taxonomia das perdas na construção, levando em consideração as especificidades do setor, bem como a Teoria Transformação, Fluxo e Valor (TFV), de Koskela (2000), enquanto Formoso et al. (2015) propõem uma estrutura conceitual para prescrever análises causais das perdas na construção. No entanto, esses trabalhos não exploram possíveis métodos para mensurar as perdas, bem como alguns tipos de perdas específicos, como perdas por transporte.

Para Ohno (1997), as perdas por transporte são todas as atividades de movimentação de materiais que geram custo e que não adicionam valor.

${ }^{1}$ Grupo Internacional de Construção Enxuta.
Segundo Guinato (2002), o transporte ocupa $45 \%$ do tempo total de fabricação de um item. As perdas de transporte estão estreitamente associadas aos fluxos e à logística de produção, e o estudo dos fluxos pode possibilitar a identificação das fontes geradoras de perdas por transporte, assim como de outras perdas na cadeia de valor (ROTHER; SHOOK, 1999).

$\mathrm{Na}$ literatura relacionada à construção civil são reportados diferentes tipos de fluxos. Perez, Costa e Gonçalves (2014), a partir de revisão da literatura sobre fluxos na construção, identificaram três principais tipos de fluxos, quais sejam:

(a) fluxo de produto: formado por subfluxos de materiais e de informação (SHINGO, 1985;

CHOO; TOMMELEIN, 1999);

(b) fluxo operacional ou fluxo de trabalho: formado pelos subfluxos de equipamentos e de mão de obra (SHINGO, 1985; KALSAAS; BØLVIKEN, 2010; BØLVIKEN; ROOKE; KOSKELA, 2014); e

(c) fluxo físico: formado pelos subfluxos de materiais e mão de obra (ALVES, 2000).

O presente trabalho foca o estudo nos fluxos físicos por possibilitar a mensuração das perdas por transportes nos fluxos de materiais e mão de obra, entendendo que fazem parte do fluxo as atividades de conversão, que envolvem o processamento dos materiais em produtos acabados e que agregam valor ao produto, e as atividades de fluxo, que envolvem as tarefas de inspeção, transporte e estoque, que são consideradas atividades que não agregam valor ao produto, devendo haver um esforço para sua redução e/ou eliminação (KOSKELA, 1992).

Nesse sentido, observa-se que, apesar do esforço da comunidade acadêmica no estudo das perdas, o número de estudos que mensuraram as perdas na construção ainda é relativamente pequeno, comparado a outros temas (VIANA; FORMOSO; KALSAAS, 2012). Além disso, muitos desses estudos têm focado apenas nas consequências ocasionadas pelas perdas, em vez de entendê-las por uma perspectiva mais sistêmica, e alguns tipos de perdas, como transporte, ainda são pouco explorados, apesar de apresentarem importância significativa.

O presente artigo tem como objetivo principal apresentar o processo de identificação, mensuração e caracterização das perdas por transporte nos fluxos físicos de processos construtivos, considerando incidências, tempos, causas e consequências. A abordagem metodológica Design

244 Pérez, C. T.; Costa, D. B.; Gonçalves, J. P. 
Science Research foi adotada, sendo realizados dois estudos de caso em processos construtivos ainda pouco empregados no Brasil. Este trabalho visa contribuir para aumentar o conhecimento existente sobre a gestão das perdas na construção, especificamente as perdas de transporte nos processos construtivos mencionados, com impactos no sistema de produção.

Este trabalho está inserido no Projeto Tecnologias para Canteiro de Obra Sustentável em Habitação de Interesse Social - Projeto CANTECHIS, apoiado pela Financiadora de Estudos e Projetos (FINEP) e executado pela UFSCar, USP, UFRGS e UFBA. Especificamente, este estudo está incluso no subprojeto Desenvolvimento de Tecnologias de Execução Relacionadas a Métodos e Sistemas Construtivos Inovadores (SPTEC).

\section{Gestão das perdas na construção}

$\mathrm{Na}$ construção civil, durante muito tempo, a medição das perdas apenas fazia referência ao consumo excessivo de materiais (BOSSINK; BROUWERS, 1996; ENSHASSI, 1996). Formoso et al. (2002) propuseram uma nova classificação de acordo com a natureza, incluindo não só as perdas de materiais, mas adaptando as sete perdas de Ohno (1988) para nove tipos de perdas, quais sejam, superprodução, espera, transporte, processamento, estoque, movimento, retrabalho (pela elaboração de produtos defeituosos), sendo acrescidas à perda por substituição e perdas de outras naturezas.

Viana, Formoso e Kalsaas (2012) apresentaram, a partir de uma revisão sistemática da literatura, diversos estudos sobre diferentes tipos de perdas, como se destaca a seguir:

(a) excesso no consumo de materiais (SKOYLES, 1976; BOSSINK; BROUWERS, 1996;

ENSHASSI, 1996; FORMOSO et al., 2002;

NAHMENS; IKUMA, 2011);

(b) atividades que não agregam valor e retrabalhos (CHOI et al., 2002; LOVE, 2002; LOVE; EDWARDS, 2004; KOSKENVESA et al., 2008; SENARATNE; SEXTON, 2009; YU et al., 2009; BULHÕES, 2009; HWANG et al., 2009;

ZHAO et al., 2010; HAN et al., 2011;

NAHMENS; MULLENS, 2011);

(c) desvio da qualidade (BURATI;

FARRINGTON; LEDBETTER, 1992; LEDBETTER, 1994);

(d) não conhecimento das necessidades do cliente (WOMACK; JONES, 2004); (e) investimento de capital desnecessário (MONDEN, 1983);

(f) roubo ou vandalismo (BOSSINK; BROUWERS 1996); e

(g) making-do (KOSKELA, 2004; SOMMER, 2010).

As tentativas de contextualizar e expandir a classificação original das sete perdas sugerem, no mínimo, que existem diferentes entendimentos sobre os tipos de perdas. Além disso, é importante avaliar se a classificação será útil na melhoria dos processos construtivos, contribuindo na identificação e redução das perdas (BØLVIKEN; ROOKE; KOSKELA, 2014).

Bølviken, Rooke e Koskela (2014) propõem uma classificação das perdas que consideram compatível com a indústria da construção, empiricamente justificável. Os referidos autores identificaram apenas três tipos de perdas: perdas de materiais, perdas de tempo e perdas de valor, a partir das perspectivas da teoria TFV (Transformação, Fluxo e Valor).

Na perspectiva da transformação, as perdas estão relacionadas à utilização de mais recursos para a produção do que o necessário, ou seja, as perdas de materiais. Na perspectiva do valor, o desperdício ocorre quando o resultado não é o esperado (BØLVIKEN; ROOKE; KOSKELA, 2014). Na perspectiva de fluxo, perda envolve o uso de mais tempo do que necessário, pois Bølviken, Rooke e Koskela (2014) entendem o tempo como um atributo e um recurso na produção. As possíveis perdas de tempo identificadas nos fluxos de trabalho são devidas a movimentos desnecessários de pessoas, trabalho desnecessário, trabalho ineficiente ou esperas. Por outro lado, as possíveis perdas de tempo que podem ser identificadas no fluxo de produto são devidas a espaço não sendo utilizado para o trabalho, materiais em estoque e transporte desnecessário de materiais (BØLVIKEN; ROOKE; KOSKELA, 2014).

Outros autores ressaltam a importância de estudar o uso do tempo dos trabalhadores da construção civil e sua perda (BARNES, 1977; SANTOS; FORMOSO; HINKS, 1996), que pode ser avaliado utilizando técnicas como a Amostragem do Trabalho.

Para Santos, Formoso e Hinks (1996), as atividades podem ser divididas em: (1) atividades produtivas, considerando as atividades que agregam valor ao produto; (2) atividades auxiliares, reunindo as atividades que, apesar de

${ }^{2}$ Refere-se a uma situação em que uma tarefa é iniciada sem que todos os recursos estejam disponíveis para que o trabalho se inicie ou continue até seu término (KOSKELA, 2004). 
não agregarem valor de maneira direta ao produto final, são necessárias para que o serviço seja executado. Entretanto, vale ressaltar que uma parcela destas atividades auxiliares pode ser considerada perda, quando refletir em quantidades superiores às necessárias; e (3) atividades improdutivas, consideradas aquelas não agregam valor e representam perdas de tempo no processo e que podem ser classificadas em (SANTOS; FORMOSO; HINKS, 1996):

(a) evitáveis: ocasionados por falta de domínio do processo, podendo ser facilmente evitados.

Ocorrem devido a falhas de planejamento, dimensionamento inadequado das equipes, falhas de suprimentos, omissões ou erros de projeto, retrabalhos, etc.;

(b) inevitáveis: ocasionados por causas imprevisíveis aleatórias ou incontroláveis, como intempéries, greves, etc.; e

(c) ociosos: referem-se à total inatividade dos operários, podendo ser intencional ou resultante de um estado físico de predisposição, como a necessidade de descanso após um esforço excessivo.

Outra importante referência em relação ao entendimento da natureza das perdas é proposta por Ishikawa (1982), que classifica as causas das perdas segundo quatro variáveis, conhecidas como as 4M (método, mão de obra, material e máquina). Para identificar essas causas, o referido autor propõe o uso da ferramenta conhecida como Diagrama Espinha de Peixe, ou Diagrama de Ishikawa, ou Diagrama de Causa e Efeito, para apresentar a relação existente entre o resultado de um processo (efeito) e os fatores (causas) do processo que, por razões técnicas, possam afetar o resultado considerado.

\section{Perdas por transporte}

Ohno (1997) considera perdas por transporte todas as atividades de movimentação de materiais que geram custo e que não adicionam valor. Formoso et al. (1996) enfatizam que as perdas são decorrentes do uso de equipamentos, materiais, mão de obra e capital em quantidades superiores àquelas necessárias à produção da edificação. Para estes autores, as perdas por transportes estão associadas ao manuseio excessivo ou inadequado dos materiais e componentes em função de uma má programação das atividades ou de um leiaute ineficiente. Bølviken, Rooke e Koskela (2014) corroboram isso entendendo como perda o transporte desnecessário.

Essas afirmações buscam contextualizar as perdas por transporte na construção entendendo que, apesar de as atividades de transportes serem atividades que não agregam valor e que haja esforço na busca de sua eliminação e redução, dificilmente os transportes serão erradicados na construção. Por entender a necessidade de certos transportes para garantir a eficiência global do processo, considera-se que as perdas de transporte são decorrentes das tarefas desnecessárias, que geram custos adicionais e não agregam valor ao produto.

As perdas relacionadas ao transporte e armazenamento dos materiais dependem, entre outros fatores, do método de embalagem, do equipamento e das ferramentas utilizadas (THOMAS; SANVIDO; SANDERS, 1989). Para Soibelman (1993) essas perdas são devidas à falta de operários disponíveis para realizar do transporte, ao transporte excessivo ou duplo manuseio, às más condições dos percursos, ao uso de equipamentos inapropriados para o transporte; ao leiaute impróprio, à forma de empacotamento; à falta de espaço para o transporte, e à falta de preparação para o recebimento dos materiais.

\section{Método de pesquisa}

Neste estudo foi adotada a abordagem Design Science Research, cujo objetivo é aumentar o conhecimento e a compreensão de determinado problema e construir tanto uma solução teórica genérica como prática por meio de um artefato tendo como contexto um problema específico (HEVNER et al., 2004).

No presente estudo foi entendido como o problema prático a grande quantidade de perdas por transporte encontradas em processos construtivos, percebida pelos estudos levantados na revisão na literatura e por três estudos exploratórios realizados inicialmente na presente pesquisa, que indicaram que $36 \%$ a $46 \%$ das atividades do processo de revestimento de argamassa projetada estavam relacionadas à atividade de transporte. Esses resultados conduziram à identificação da lacuna relativa à necessidade de desenvolver um processo para identificação, mensuração e caracterização das perdas por transporte nos fluxos físicos de processos construtivos, sendo esse o artefato da pesquisa. A pesquisa foi desenvolvida de acordo com as etapas detalhadas a seguir.

\section{Revisão da literatura e escolha das técnicas e ferramentas adotadas}

Foi realizada uma revisão da literatura visando identificar métodos, técnicas, ferramentas e indicadores na literatura da gestão da construção para mensuração dos fluxos e perdas e aquelas 
selecionadas para este trabalho são apresentadas a seguir:

(a) Ferramenta Diagrama de Processo

(ISHIWATA, 1991): permite modelar o processo, tornando explícito o número e o tipo de atividades de processamento, inspeção, estoque e transporte, representando a sequência das diferentes atividades que compõem os processos estudados por meio do uso de símbolos. Sua utilidade é mensurar a percentagem das atividades de transporte em relação às atividades do processo;

(b) Ferramenta Mapofluxograma (ISHIWATA, 1991): permite modelar o processo e identificar o local de cada atividade, identificada por meio dos símbolos que representam as atividades e posicionadas em uma planta. Sua utilidade é identificar locais com maior ocorrência de perdas por transporte;

(c) Técnica da Amostragem do Trabalho (SANTOS; FORMOSO; HINKS, 1996): permite determinar como o operário utiliza seu tempo e identifica os problemas e pontos a ser melhorados, sendo divididos em tempos produtivos, auxiliares e improdutivos, conforme já apresentado no item Gestão das perdas na construção. Com ela é possível mensurar a percentagem dos tempos produtivos, auxiliares (transporte inclusive) e improdutivos; e

(d) Ferramenta Planilha com Registro Fotográfico (SOMMER, 2010): visa armazenar em um banco de dados as imagens referentes às perdas nas atividades de transporte.

\section{Desenvolvimento dos estudos de caso}

A escolha das obras para a realização dos estudos de caso foi conduzida pelo critério de utilização de tecnologias ainda pouco empregadas no Brasil e pouco exploradas do ponto de vista das perdas por transporte. No Estudo 1 o foco foi o processo de revestimento de argamassa por sistema de projeção mecânica. No Estudo 2 o foco foi a tecnologia Light Steel Frame (LSF) ${ }^{3}$, especificamente os processos de (a) instalação da estrutura metálica, (b) instalação das placas de Oriented Strand Board $(\mathrm{OSB})^{4},(\mathrm{c})$ execução de telhado, e (d) execução de fachada, que foram escolhidos pelo fato de ser realizados em uma área reduzida do canteiro, tornando delimitado e mais preciso o foco de investigação. O Quadro 1 resume as características das obras e da coleta geral de dados, e o Quadro 2 apresenta as principais etapas dos estudos,

${ }^{3}$ Estrutura de aço leve.

${ }^{4}$ Placas de Partículas Orientadas. destacando-se os períodos de coleta, as fontes de evidência e as ferramentas utilizadas.

\section{Identificação dos fluxos físicos}

A identificação e a modelagem dos fluxos físicos ocorreram durante a primeira semana de cada estudo, sendo necessárias três visitas de $2 \mathrm{~h}$ no Estudo 1 e duas visitas de $4 \mathrm{~h}$ no Estudo 2, nas quais foram utilizadas as ferramentas Diagrama de Processo e Mapofluxograma.

A equipe de pesquisadores buscou entender o processo por meio de entrevistas não estruturadas com estagiários e encarregados, que forneceram informações específicas sobre como as atividades eram desenvolvidas, bem como pela observação direta. Utilizou-se o registro fotográfico para documentar a sequência de atividades desenvolvidas no processo no canteiro, identificando-se os fluxos das atividades.

Depois dessa coleta, a equipe de pesquisadores realizou o processo de modelagem dos fluxos, possibilitando a identificação das atividades que agregavam e não agregavam valor aos processos estudados, dando destaque às atividades de transporte. A equipe de pesquisadores validou a modelagem dos fluxos identificados por meio de novas observações diretas em campo para confirmação das atividades e pela apresentação e discussão do mapeamento com os encarregados e estagiários da obra.

\section{Identificação da distribuição dos tempos dos trabalhadores}

A identificação da distribuição dos tempos dos trabalhadores foi realizada por meio da técnica da Amostragem do Trabalho. A coleta foi realizada por meio de observações instantâneas da equipe de trabalho, registradas na planilha com registro fotográfico, em um intervalo de tempo aleatório durante visitas de 4 h de duração. Para o cálculo do número de observações no Estudo 1 foi adotado um nível de confiança de $95 \%$ e um erro relativo de $5 \%$, sendo realizadas 2.314 observações, envolvendo todas as pessoas que participavam no processo de argamassa projetada. Das 16 pessoas envolvidas apenas 8 trabalhavam diretamente no processo de produção, conforme apresentado no Quadro 3. No Estudo 2 foi adotado um nível de confiança do $94 \%$ e um erro relativo de $6 \%$, sendo realizadas 1.873 observações, que envolveram todas as pessoas que participavam diretamente nos processos estudados (Quadro 3), não considerando a equipe de logística da obra, devido ao fato de estas destinarem grande parte de seu tempo na realização de outras atividades não relacionadas ao processo estudado. 
Quadro 1 - Características dos Estudos de Caso 1 e 2

\begin{tabular}{|c|c|c|c|c|}
\hline Estudo & Obra & Sistema Estudado & $\begin{array}{l}\text { Caraterização } \\
\text { da Coleta }\end{array}$ & $\begin{array}{l}\text { Pessoas da obra } \\
\text { envolvidas }\end{array}$ \\
\hline $\begin{array}{l}\text { Estudo de } \\
\text { Caso } 1\end{array}$ & $\begin{array}{l}\text { Empreendimento } \\
\text { residencial } \\
\text { composto de } 8 \\
\text { torres com } 16 \\
\text { pavimento cada. } \\
\text { Salvador-BA. }\end{array}$ & $\begin{array}{l}\text { Sistema de projeção } \\
\text { mecânica para o } \\
\text { revestimento interno } \\
\text { com argamassa }\end{array}$ & $\begin{array}{l}\text { Coleta dos } \\
\text { Dados: } \\
13 \text { semanas } \\
32 \text { visitas } \\
\text { Vistas de } 4 \text { a } 6 \mathrm{~h}\end{array}$ & $\begin{array}{l}1 \text { Engenheiro de } \\
\text { Produção } \\
1 \text { Estagiário da obra } \\
1 \text { Estagiário da } \\
\text { empresa de projeção } \\
1 \text { Encarregado }\end{array}$ \\
\hline $\begin{array}{l}\text { Estudo de } \\
\text { Caso } 2\end{array}$ & $\begin{array}{l}\text { Empreendimento } \\
\text { residencial } \\
\text { composto de } 178 \\
\text { casas. } \\
\text { Canoas-RS. }\end{array}$ & $\begin{array}{l}\text { Light Steel Frame. } \\
\text { Instalação da estrutura } \\
\text { metálica; } \\
\text { Instalação do OSB; } \\
\text { Execução do telhado; } \\
\text { Execução da fachada }\end{array}$ & $\begin{array}{l}\text { Coleta dos } \\
\text { Dados: } \\
6 \text { semanas } \\
25 \text { visitas } \\
\text { Visitas de } 4 \text { a } 6 \mathrm{~h}\end{array}$ & $\begin{array}{l}1 \text { Gestor da obra } \\
3 \text { Engenheiros da obra } \\
1 \text { Estagiário da obra } \\
1 \text { Encarregado }\end{array}$ \\
\hline
\end{tabular}

Quadro 2 - Etapas dos estudos: períodos, fontes de evidência e ferramentas

\begin{tabular}{|c|c|c|c|c|}
\hline Etapas do Estudo & $\begin{array}{l}\text { Período } \\
\text { Estudo } 1\end{array}$ & $\begin{array}{l}\text { Período } \\
\text { Estudo } 2\end{array}$ & Fontes de evidência & $\begin{array}{l}\text { Técnicas ou } \\
\text { Ferramentas }\end{array}$ \\
\hline Apresentação estudo & $30 / 04 / 14$ & $03 / 11 / 14$ & - & - \\
\hline $\begin{array}{l}\text { Identificação dos } \\
\text { fluxos físicos }\end{array}$ & $\begin{array}{l}06 / 05 \text { a } \\
12 / 05 / 14\end{array}$ & $\begin{array}{l}03 / 11 \mathrm{a} \\
07 / 11 / 14\end{array}$ & $\begin{array}{l}\text { Análise de documentos } \\
\text { Observação direta } \\
\text { Anotações de campo } \\
\text { Documentação fotográfica }\end{array}$ & $\begin{array}{l}\text { Diagrama de } \\
\text { Processo } \\
\text { Mapofluxograma }\end{array}$ \\
\hline $\begin{array}{l}\text { Identificação da } \\
\text { distribuição dos } \\
\text { tempos dos } \\
\text { trabalhadores }\end{array}$ & $\begin{array}{l}13 / 05 \mathrm{a} \\
17 / 07 / 14\end{array}$ & $\begin{array}{l}24 / 11 \mathrm{a} \\
12 / 12 / 14\end{array}$ & $\begin{array}{l}\text { Observação direta } \\
\text { Anotações de campo } \\
\text { Documentação fotográfica }\end{array}$ & $\begin{array}{l}\text { Amostragem do } \\
\text { trabalho }\end{array}$ \\
\hline $\begin{array}{l}\text { Caracterização das } \\
\text { perdas por transporte }\end{array}$ & $\begin{array}{l}06 / 08 \mathrm{a} \\
05 / 09 / 14\end{array}$ & $\begin{array}{l}10 / 11 \mathrm{a} \\
21 / 11 / 14\end{array}$ & $\begin{array}{l}\text { Observação direta } \\
\text { Anotações de campo } \\
\text { Documentação fotográfica } \\
\text { Percepção dos envolvidos no } \\
\text { estudo por meio de entrevistas } \\
\text { não estruturadas } \\
\text { Observação participante nas } \\
\text { reuniões de planejamento no } \\
\text { Estudo } 2 \\
\text { Análise de PPC e causas de não } \\
\text { cumprimento no Estudo } 2\end{array}$ & $\begin{array}{l}\text { Planilha com } \\
\text { registro } \\
\text { fotográfico }\end{array}$ \\
\hline $\begin{array}{l}\text { Seminário de } \\
\text { apresentação de } \\
\text { resultados }\end{array}$ & $\begin{array}{l}18 / 07 \mathrm{e} \\
12 / 09 / 14\end{array}$ & $15 / 12 / 14$ & $\begin{array}{l}\text { Percepção dos envolvidos no } \\
\text { estudo pelas discussões }\end{array}$ & \\
\hline Avaliação do estudo & $21 / 05 / 15$ & $21 / 05 / 15$ & $\begin{array}{l}\text { Entrevistas estruturadas com um } \\
\text { engenheiro e um estagiário por } \\
\text { obra }\end{array}$ & $\begin{array}{l}\text { Questionário } \\
\text { estruturado }\end{array}$ \\
\hline
\end{tabular}

Quadro 3 - Trabalhadores envolvidos na amostragem do trabalho nos Estudos 1 e 2

\begin{tabular}{|c|c|c|}
\hline \multicolumn{2}{|c|}{ Estudo de Caso 1} & Estudo de Caso 2 \\
\hline $\begin{array}{l}\text { Equipe direta no } \\
\text { processo }\end{array}$ & Equipe indir eta no processo & $\begin{array}{l}\text { Equipe dir eta nos quatro } \\
\text { processos estudados }\end{array}$ \\
\hline $\begin{array}{l}1 \text { responsável pela } \\
\text { produção de argamassa } \\
5 \text { pedreiros } \\
2 \text { serventes }\end{array}$ & $\begin{array}{l}1 \text { motorista de caminhão } \\
2 \text { operadores da carregadeira } \\
3 \text { operadores de macaco hidráulico } \\
1 \text { operador de elevador cremalheira } \\
1 \text { pedreiro na aplicacão das taliscas }\end{array}$ & $\begin{array}{l}4 \text { montadores da estrutura metálica } \\
4 \text { montadores das placas de OSB } \\
4 \text { montadores do telhado } \\
4 \text { montadores da fachada }\end{array}$ \\
\hline
\end{tabular}


A folha utilizada para o registro de observações foi individualmente desenhada para cada um dos estudos em função das atividades levantadas no Diagrama de Processo e Mapofluxograma, dando destaque às atividades de transporte, por meio de subdivisões dessas atividades. Caso uma atividade não tivesse sido incialmente identificada no mapeamento, era inserida na folha com um novo número de identificação. Um exemplo de subdivisão realizada no Estudo 1 refere-se ao transporte dos sacos no carrinho de mão, que foi dividido em transporte manual dos sacos até o carrinho, transporte dos sacos com carrinho e transporte manual dos sacos desde o carrinho até o estoque. Essa discriminação possibilitou a identificação das atividades de transporte e sua correta classificação.

Ao longo da modelagem dos fluxos e mensuração dos tempos de trabalho foram identificadas pela equipe de pesquisa atividades de transportes que podiam ser consideradas necessárias, evitáveis e desnecessárias. Durante e após a amostragem do trabalho buscou-se identificar essas diferentes atividades e mensurar a perda de tempo delas, tendo como base a observação direta, as fotografias e as filmagens realizadas. Visando delimitar e tonar mais claras as atividades de transporte foram estabelecidas definições tendo como base as definiçõos de Santos, Formoso e Hinks (1996), quais sejam:

(a) transportes necessários: transportes que precisavam ocorrer para que o processo fluísse. Esses transportes foram classificados nas atividades auxiliares, gerando tempos auxiliares;

(b) transportes evitáveis: transportes ineficientes, que provocam perdas de tempo, ocasionados, algumas vezes, por falta de domínio do processo, podendo ser facilmente reduzíveis. Ocorrem devido a falhas de planejamento, dimensionamento inadequado das equipes, falhas de suprimentos ou equipamentos, omissões ou erros de projeto, retrabalhos, etc. Essas atividades de transportes geram obstruções do fluxo. Esses transportes foram classificados nas atividades auxiliares, gerando tempos auxiliares; e

(c) transportes desnecessários ou ociosidade: referem-se a atividades de transporte desnecessárias ou à total inatividade dos operários relativa a alguma atividade de transporte, podendo ser intencional ou resultantes de um estado físico de predisposição (por exemplo, necessidade de descanso após um esforço excessivo). Essas atividades foram classificadas nas atividades improdutivas, gerando tempos improdutivos.

\section{Caracterização das perdas por transporte}

Para a caracterização das perdas por transporte foram definidos três conceitos, baseados nos dados obtidos nas etapas anteriores, conforme a seguir:

(a) causa da perda: é definida como a causa direta observada de determinado evento de perda de transporte em determinada situação;

(b) evento de perda de transporte: é definido como um fenômeno que acontece na atividade de transporte, tratando-se de um fato observável e registrável em determinado local e em determinado momento que afeta os fluxos físicos, provocando a execução de tarefas não planejadas e produzindo ineficiências ao processo; e

(c) consequência da perda: é definida como o efeito, impacto ou resultado de determinado evento de perda de transporte, podendo gerar a criação de novos eventos de perdas.

É importante destacar que, apesar das definições e delimitações estabelecidas pelos conceitos, tanto as causas quanto as consequências podem ter origens/impactos mais amplos, sistêmicos e não únicos. No Estudo 1 foram analisados apenas os conceitos "evento de perda por transporte" e "causa". O conceito consequência foi percebido como importante ao final do Estudo 1, devido à dificuldade de isolar as perdas por transporte, considerando necessário caracterizar a perda como um todo.

A organização dos eventos de perdas por transporte foi realizada por meio da planilha com registro fotográfico. A coleta desses eventos foi realizada durante 4 semanas no Estudo 1 e 2 semanas no Estudo 2, ao longo de todo o tempo de permanência da pesquisadora no canteiro, principal autora deste trabalho, que envolveu visitas diárias de 4 a $6 \mathrm{~h}$.

Cada vez em que era identificado um evento de perda por transporte, esse era registrado instantaneamente por meio de uma foto e armazenado na planilha, que foi dividida em colunas, sendo coletadas as seguintes informações: foto, data, número de registro, número casos/dia, pessoas envolvidas no transporte, tipo de transporte, caso recorrente e descrição da perda, causa da perda e tempo de perda (Figura 1). No Estudo 2 foi acrescentada a coluna consequência.

Para o cálculo do tempo dos eventos de perdas por transporte foram cronometrados os tempos de cada atividade de transporte em várias ocasiões na amostragem, obtendo-se a média de tempo dessa atividade. Depois, cada vez em que era identificada uma perda, o tempo de realização da atividade de transporte era medido e subtraído do 
tempo médio de realização dela, obtendo-se um tempo estimado destinado à atividade como perda.

Após coleta inicial do Estudo 1, constatou-se que vários eventos de perdas por transporte identificados ocorriam de forma repetitiva. Por esse motivo, a equipe de pesquisa buscou agrupar esses eventos segundo as causas observadas, respondendo à questão "qual é causa observável deste evento de perda por transporte?". Essas causas foram discutidas no Estudo de Caso $1 \mathrm{com}$ uma estagiária da obra. Como base nesse processo de organização dos eventos, e a partir da análise sistêmica dos dados de perdas por transporte e tomando como base a classificação das $4 \mathrm{M}$ de Ishikawa (1982), foi proposta uma classificação com sete principais causas das perdas identificadas de acordo com a observação dos eventos, conforme apresenta o Quadro 4. Essas causas foram refinadas e validadas no Estudo 2, adotandose o mesmo processo e com a realização de um diagrama de espinha de peixe, a partir de um brainstorming das possíveis causas com a aluna de doutorado participante do estudo (Figura 2).

Figura 1 - Exemplo de planilha com registros fotográficos

\begin{tabular}{|c|c|c|c|c|c|c|c|c|c|}
\hline 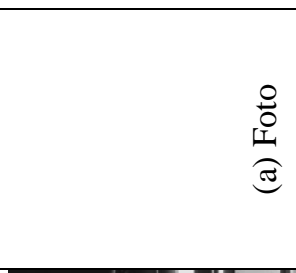 & $\frac{\tilde{\pi}}{\stackrel{\tilde{*}}{0}}$ & $\begin{array}{l}0 \\
\stackrel{0}{0} \\
.00 \\
0 \\
0 \\
0 \\
0 \\
0 \\
Z \\
0 \\
0\end{array}$ & 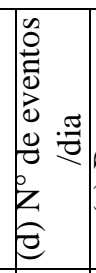 & 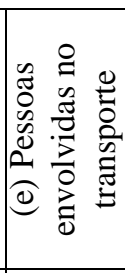 & 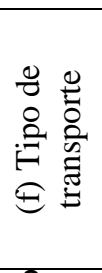 & 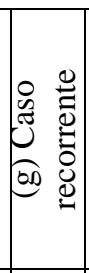 & 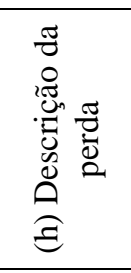 & 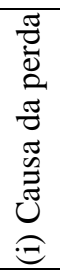 & 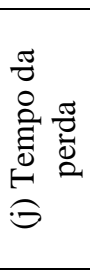 \\
\hline & & 工 & - & $n$ & 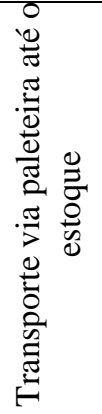 & $\stackrel{\Xi}{\leftrightarrows}$ & 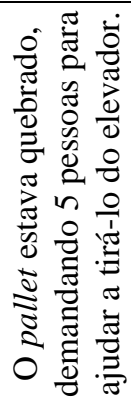 & 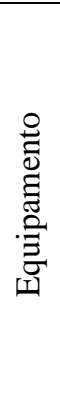 & $\begin{array}{l}\stackrel{\Upsilon}{0} \\
\ddot{8} \\
\dot{8}\end{array}$ \\
\hline
\end{tabular}

Figura 2 - Espinha de Peixe das causas das perdas por transporte

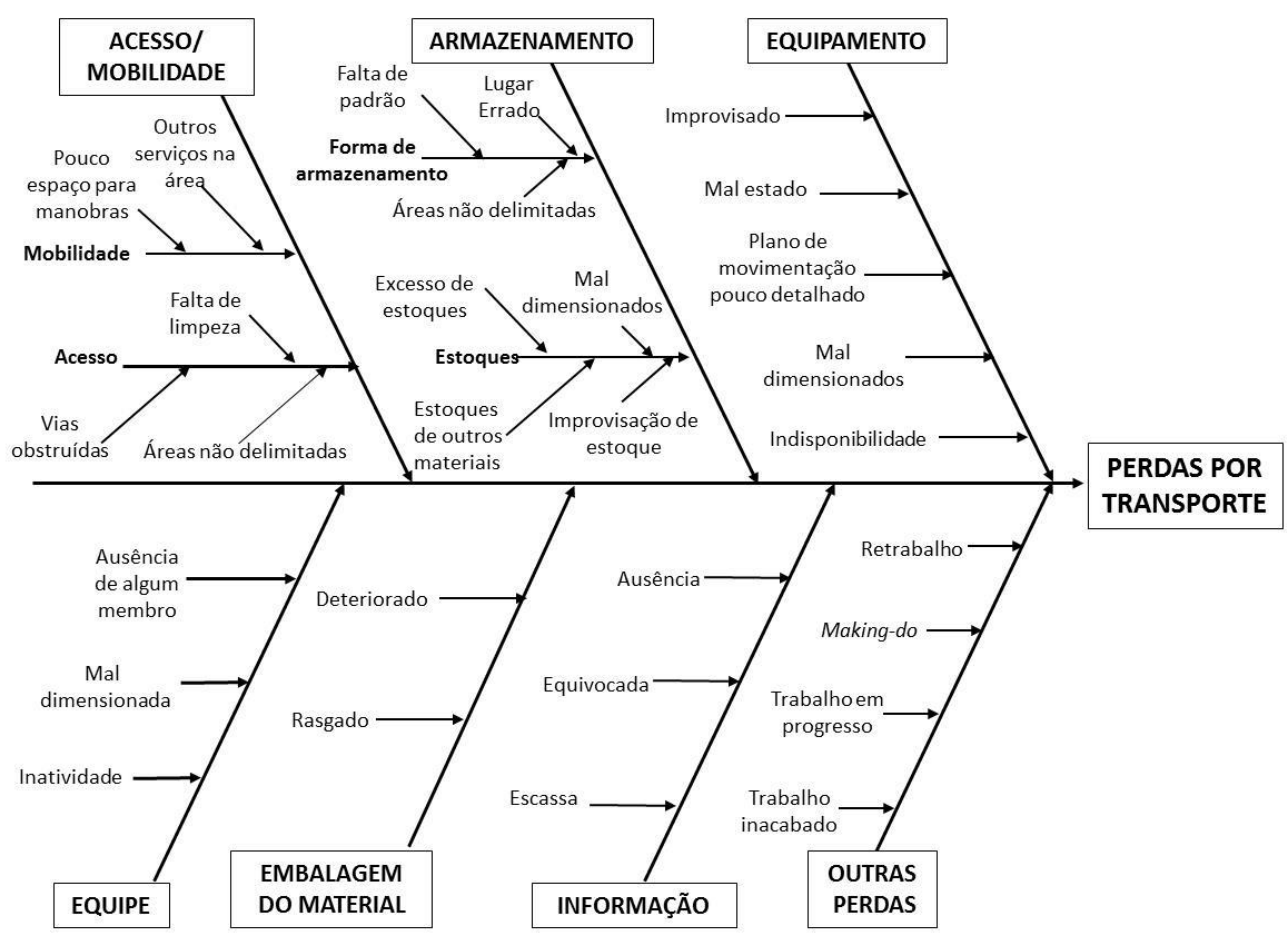

250 Pérez, C. T.; Costa, D. B.; Gonçalves, J. P. 
No Estudo 2 buscou-se identificar quais seriam as possíveis consequências dos eventos de perdas identificadas neste estudo, que também foi realizada a partir da observação direta dos eventos de perda pela equipe de pesquisa, buscando responder à questão "quais são as consequências diretas dos eventos de perdas por transporte?". Essa identificação foi realizada instantaneamente, observando os impactos ocorridos nos segundos posteriores ao evento ter sido identificado e refinada durante análise dos dados, pressupondo quais outros impactos poderiam acontecer. Percebeu-se durante a análise que o evento de perda poderia estar relacionado com outras consequências, então se optou por relacionar o evento de perda por transporte com até três consequências. As consequências de cada evento de perda também foram discutidas com a doutoranda participante do estudo, identificadas e agrupadas conforme o Quadro 5.
Durante o Estudo 2 foi observado que algumas perdas por transportes estavam associadas a outras perdas, tais como making-do, perda por retrabalho, perda por trabalho inacabado e perda por trabalho em progresso. Essas categorias de perdas foram identificadas em alguns momentos como causa e em outros como consequência dos eventos de perda por transporte.

\section{Definição dos indicadores para mensuração das perdas por transporte}

Com base na técnica e nas ferramentas utilizadas no estudo foram identificados quatro indicadores para mensurar as perdas por transporte (Quadro 6) Adicionalmente, foi possível identificar as principais causas, consequências e locais com maior ocorrência das perdas por transporte por meio dos dados coletados.

Quadro 4 - Classificação das causas das perdas por transporte

\begin{tabular}{|l|l|}
\hline Causa & Definição \\
\hline Acesso/mobilidade & $\begin{array}{l}\text { Relaciona-se com a falta de mobilidade para o transporte, devido a restrito } \\
\text { acesso por presença de obstáculos ou layout inadequado do canteiro. }\end{array}$ \\
\hline Armazenamento & $\begin{array}{l}\text { Refere-se a estoque em lugares que não estão preparados para o } \\
\text { armazenamento ou estoque armazenado de forma errada em locais } \\
\text { apropriados. }\end{array}$ \\
\hline Equipamento & $\begin{array}{l}\text { Relaciona-se a equipamento indisponível, defeituoso ou não adequado ao } \\
\text { transporte, gerando a necessidade de adaptação de outro equipamento para } \\
\text { o transporte. Ou ainda equipamento apto para o uso, porém utilizado de } \\
\text { forma errada. }\end{array}$ \\
\hline Embalagem do material & $\begin{array}{l}\text { Refere-se às más condições de embalagem ou empacotamento do material } \\
\text { a ser transportado, dificultando o transporte do mesmo. }\end{array}$ \\
\hline Equipe & $\begin{array}{l}\text { Refere-se a número insuficiente de trabalhadores disponíveis que atenda às } \\
\text { necessidades do transporte. }\end{array}$ \\
\hline Informação & $\begin{array}{l}\text { Refere-se a escassa, equivocada ou ausência de informação fornecida ao } \\
\text { trabalhador, criando um evento de perda }\end{array}$ \\
\hline Outras perdas & $\begin{array}{l}\text { Relaciona-se a outro tipo de perda que gerou uma perda de transporte, tais } \\
\text { como retrabalho, making-do, por trabalho inacabado e por trabalho em } \\
\text { progresso. }\end{array}$ \\
\hline
\end{tabular}

Quadro 5 - Classificação das consequências das perdas por transporte

\begin{tabular}{|l|l|}
\hline Consequências & Definição \\
\hline Danificação do material & Provoca a danificação ou deterioração do material durante o transporte. \\
\hline $\begin{array}{l}\text { Redução das condições } \\
\text { de segurança }\end{array}$ & $\begin{array}{l}\text { Produz uma condição insegura para o trabalhador durante a atividade de } \\
\text { transporte. }\end{array}$ \\
\hline $\begin{array}{l}\text { Necessidade de um novo } \\
\text { transporte }\end{array}$ & $\begin{array}{l}\text { Provoca um novo transporte devido a problemas encontrados no transporte } \\
\text { anterior. }\end{array}$ \\
\hline $\begin{array}{l}\text { Necessidade de um } \\
\text { percurso maior }\end{array}$ & Gera um transporte com uma distância maior do que a planejada. \\
\hline Problema ergonômico & $\begin{array}{l}\text { Provoca um problema ergonômico durante execução da atividade de } \\
\text { transporte. }\end{array}$ \\
\hline Outras perdas & $\begin{array}{l}\text { Provoca a geração de outras perdas, tais como: making-do, trabalho em } \\
\text { progresso, etc. }\end{array}$ \\
\hline
\end{tabular}


Quadro 6 - Indicadores para mensuração das perdas por transporte

\begin{tabular}{|c|c|c|c|}
\hline Indicador & Objetivo / Forma de coleta & Fórmula utilizada & Variáveis \\
\hline $\begin{array}{l}\text { Percentual } \\
\text { das atividades } \\
\text { de transporte }\end{array}$ & $\begin{array}{l}\text { Identificar o } \mathrm{n}^{\circ} \text { de atividades de } \\
\text { transporte do processo } \\
\text { estudado em relação ao número } \\
\text { total de atividades. } \\
\text { Obtido pelo Diagrama do } \\
\text { Processo. }\end{array}$ & $\frac{\left(N^{\circ} \text { AT }\right) \times 100}{\left(N^{\circ} \text { Total de A }\right)}$ & $\begin{array}{l}\text { AT }=\text { Atividades } \\
\text { de Transporte } \\
\text { A =Atividades do } \\
\text { Processo }\end{array}$ \\
\hline $\begin{array}{l}\text { Percentual do } \\
\text { tempo } \\
\text { produtivo da } \\
\text { equipe direta }\end{array}$ & $\begin{array}{l}\text { Identificar o tempo gasto em } \\
\text { atividades produtivas pela } \\
\text { equipe direta em relação ao } \\
\text { tempo total da equipe direta. } \\
\text { Obtida pela Amostragem do } \\
\text { Trabalho. }\end{array}$ & $\frac{(№ \text { de observações de TP da ED }) \times 100}{\left(N^{\circ} \text { Total de Observações da ED }\right)}$ & $\begin{array}{l}\mathrm{TP}=\text { Tempos } \\
\text { Produtivos } \\
\mathrm{ED}=\text { Equipe } \\
\text { Direta }\end{array}$ \\
\hline $\begin{array}{l}\text { Percentual do } \\
\text { tempo total } \\
\text { em atividades } \\
\text { de transporte }\end{array}$ & $\begin{array}{l}\text { Identificar o tempo gasto em } \\
\text { atividades de transporte } \\
\text { (necessários, evitáveis, } \\
\text { desnecessários) pela equipe } \\
\text { direta em relação ao tempo } \\
\text { total da equipe direta. } \\
\text { Obtida pela Amostragem do } \\
\text { Trabalho. }\end{array}$ & $\begin{array}{c}(N o \text { de observações } \\
\frac{\text { de }(T P+T E+T D) \text { da ED }) \times 100}{\left(N^{\circ} \text { Total de Observações da ED) }\right.}\end{array}$ & $\begin{array}{l}\mathrm{TN}=\text { Transportes } \\
\text { Necessários } \\
\mathrm{TE}=\text { Transportes } \\
\text { Evitáveis } \\
\mathrm{TD}=\text { Transportes } \\
\text { Desnecessários } \\
\mathrm{ED}=\text { Equipe } \\
\text { Direta }\end{array}$ \\
\hline $\begin{array}{l}\text { Percentual do } \\
\text { tempo } \\
\text { perdido em } \\
\text { atividades de } \\
\text { transporte }\end{array}$ & $\begin{array}{l}\text { Identificar o tempo perdido em } \\
\text { atividades de transporte } \\
\text { evitáveis e desnecessários em } \\
\text { relação ao tempo total da } \\
\text { equipe direta. } \\
\text { Obtida pela Amostragem do } \\
\text { Trabalho. }\end{array}$ & $\begin{array}{c}(N o \text { de observaç̃oes } \\
\frac{d e(T E+T D) \text { da ED }) \times 100}{(N o \text { Total de Observações da ED) }}\end{array}$ & $\begin{array}{l}\mathrm{TE}=\text { Transportes } \\
\text { Evitáveis } \\
\mathrm{TD}=\text { Transportes } \\
\text { Desnecessários } \\
\mathrm{ED}=\text { Equipe } \\
\text { Direta }\end{array}$ \\
\hline
\end{tabular}

\section{Seminários e questionários para avaliação do estudo}

A avaliação do estudo foi realizada a partir dos constructos utilidade e facilidade de uso, com base em dados coletados nas discussões durante os seminários de apresentação dos resultados e a aplicação de um questionário nos Estudos 1 e 2 sobre as ferramentas, indicadores e conceitos utilizados com os engenheiros e estagiários das obras.

\section{Apresentação dos resultados}

\section{Estudo de caso 1}

\section{Características do processo e identificação dos fluxos físicos}

O processo estudado caracterizava-se por utilizar a argamassa ensacada em sacos de $25 \mathrm{~kg}$ para o revestimento. A central de produção de argamassa e os depósitos de água estavam situados no andar a ser revestido. Os sacos chegavam ao canteiro em pallets por caminhão. $\mathrm{O}$ transporte horizontal de cada pallet desde o caminhão até a garagem era realizado com o uso de uma carregadeira. Tanto o transporte horizontal do pallet de sacos na garagem quanto aqueles até dentro do elevador cremalheira e do elevador até a área de estocagem no andar eram realizados com uma paleteira. $\mathrm{O}$ transporte vertical do pallet de sacos era via elevador cremalheira. O transporte horizontal dos sacos no andar até perto da argamassadeira era realizado de forma individual, podendo ser este de forma manual, via carrinho de mão ou padiola. Por fim, os sacos do estoque perto da argamassadeira eram transportados até a central, e a água era transportada com um balde não graduado.

Por meio do Diagrama do Processo e do Mapofluxograma (Figura 3) foram identificadas 3 atividades de processamento (15\% das atividades), 
14 atividades de transporte ( $45 \%$ das atividades), 6 atividades de inspeção ( $20 \%$ das atividades) e 6 atividades de estoque (20\% das atividades). Esses resultados apontaram para o elevado número de atividades de transportes realizadas.

\section{Distribuição dos tempos dos trabalhadores}

A Tabela 1 resume os resultados das observações realizadas durante a Amostragem do Trabalho no Estudo de Caso 1, de acordo com os critérios estabelecidos no método de pesquisa para tempos produtivos, auxiliares e improdutivos, e análise dos tempos das atividades de transporte em função de transportes necessários, transportes evitáveis e transportes desnecessários.

Analisando-se os resultados obtidos para a equipe direta, observa-se que $29 \%$ dos tempos são destinados a atividades produtivas, $52 \%$ a atividades auxiliares, e $19 \%$ a atividades improdutivas. Os resultados individuais do pedreiro encarregado da produção da argamassa, dos pedreiros de revestimento e dos serventes apontam um alto percentual de tempo gasto em atividades auxiliares, representando respectivamente $60 \%, 29 \%$ e $75 \%$ das observações.

Especificamente, analisando-se todos os transportes, observa-se que o pedreiro de produção da argamassa, os pedreiros de execução do revestimento e os serventes utilizam respectivamente $45 \%, 13 \%$ e $52 \%$ de seus tempos em transportes. Considerando que os transportes evitáveis e desnecessários provocam perdas de tempo, eles representaram $11 \%, 12 \%$ e $33 \%$ nas atividades do pedreiro de produção da argamassa, dos pedreiros de revestimento e dos serventes respectivamente.

Figura 3 - Mapofluxogramas do térreo e do andar no Estudo 1
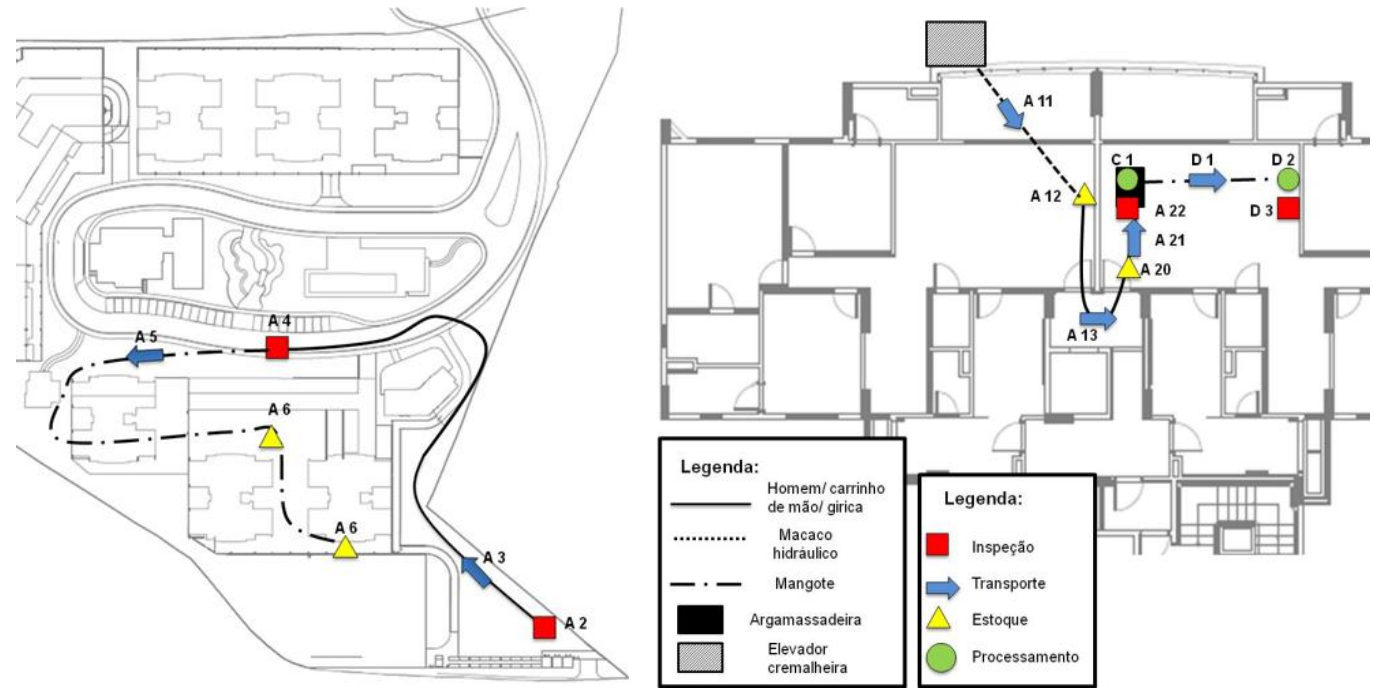

Tabela 1 - Resumo dos resultados da Amostragem de Trabalho no Estudo 1

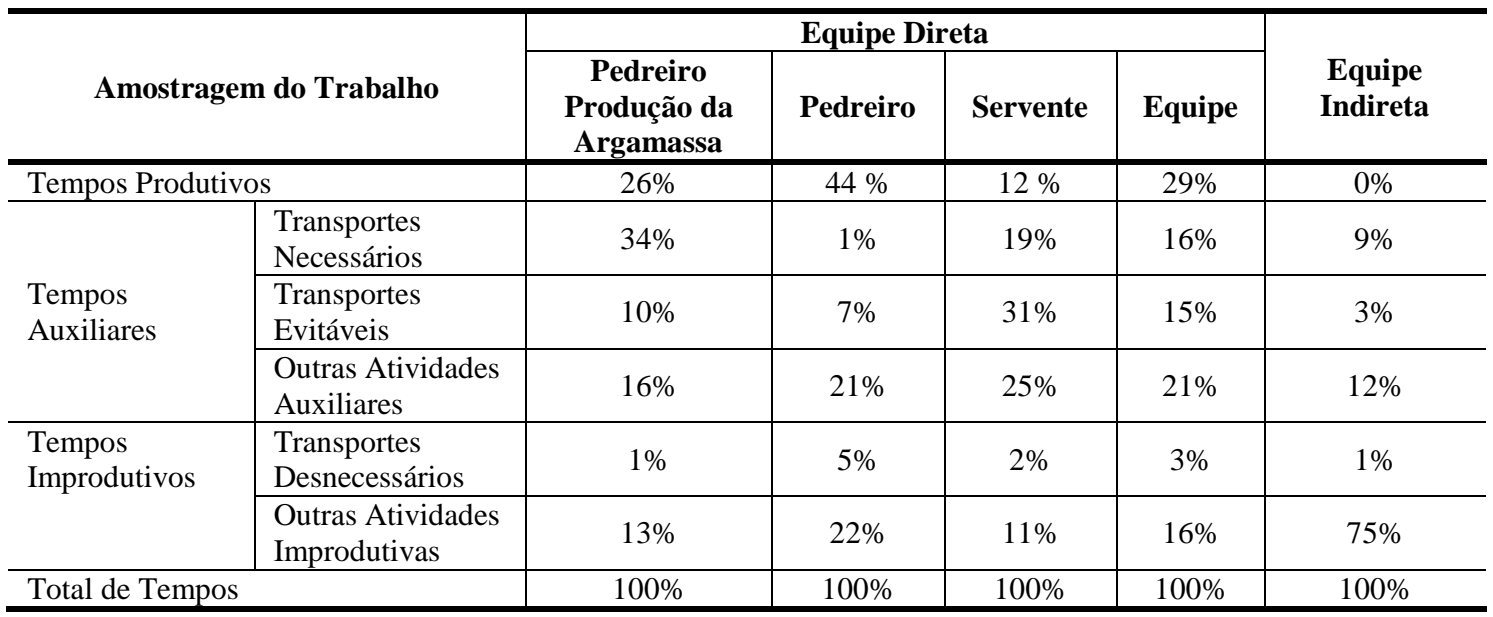


A Figura 4 apresenta o percentual de tempo das principais atividades de transporte necessárias, evitáveis e desnecessárias em relação ao tempo total da equipe direta identificadas no estudo.

O transporte de água em balde desde os tonéis até a argamassadeira e o transporte manual até a argamassadeira representaram cada um $4 \%$ dos tempos destinados em transportes necessários. $\mathrm{O}$ tempo destinado a outros transportes necessários, tais como transporte do caminhão no canteiro, transporte dos pallets em carregadeira e transporte pela cremalheira, representou $5 \%$ do tempo total. $\mathrm{O}$ transporte manual até perto da argamassadeira, o transporte dos sacos vazios, o transporte do equipamento e o transporte do equipamento vazio representaram cada um $2 \%$ dos tempos destinados a transportes evitáveis. O transporte em equipamento com pallets pela garagem e até o elevador cremalheira, assim como o transporte via padiola no andar, entre outros transportes evitáveis, representaram todos eles $7 \%$ do tempo total. Por fim, o transporte de um estoque terciário para um quaternário representou $2 \%$ do tempo destinado a transportes desnecessários.

\section{Caracterização das perdas por transporte}

Durante o registro fotográfico das perdas de transporte foram identificados 83 eventos de perdas por transporte, agrupados segundo a causa.
Constatou-se que muitos eventos de perdas eram recorrentes, sendo mensurada sua incidência, além da quantificação do tempo gasto na atividade em cada um dos eventos (Quadro 7). Observa-se que, embora a perda por (falta de) acesso/mobilidade tenha tido maior incidência (35 observações), a perda devido ao equipamento ocasiona maior perda de tempo quando é identificada ( 4 h $38 \mathrm{~m} \mathrm{e}$ 23 s). O somatório dos tempos em eventos de perdas por transporte correspondeu a $6 \mathrm{~h} 52 \mathrm{~m} \mathrm{e} 6$ $\mathrm{s}$ trabalhadas, enquanto o tempo total para revestir os três pavimentos foi de $77 \mathrm{~h}$ trabalhadas.

Foram ainda identificados os locais com maior incidência de perdas. $O$ transporte no andar representou $63 \%$ das perdas por transportes, totalizando 52 eventos identificados. $\mathrm{O}$ transporte no térreo representou $35 \%$, e o transporte vertical, $2 \%$. Não foram identificadas perdas nas atividades de transporte dos sacos até a argamassadeira. Entre as atividades de transporte no andar que apresentaram maior incidência de perdas destacaram-se o transporte manual do estoque para o carrinho de mão (14 eventos) e o transporte manual do carrinho de mão para o estoque perto da argamassadeira (14 eventos).

Figura 4 - Percentagem de tempos destinados às principais atividades de transporte necessárias, evitáveis e desnecessárias em relação ao tempo total da equipe direta

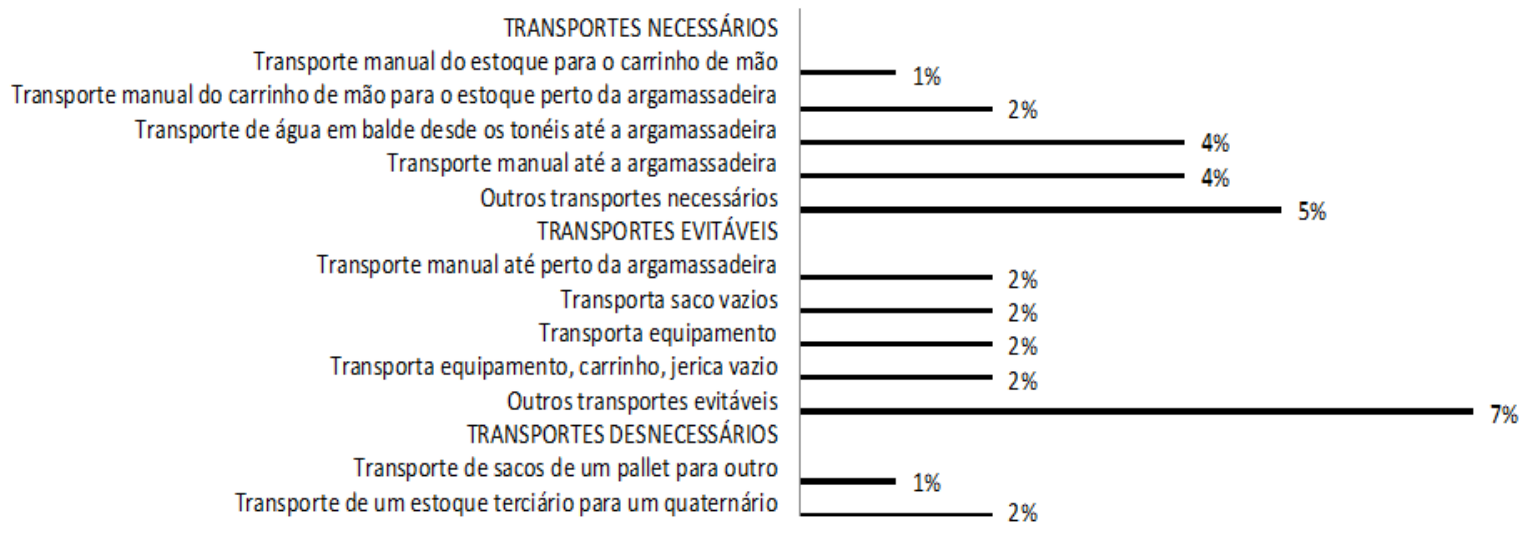

254 Pérez, C. T.; Costa, D. B.; Gonçalves, J. P. 
Quadro 7 - Eventos de perdas de transporte, sua incidência e tempo da perda no Estudo 1

\begin{tabular}{|c|c|c|c|c|c|}
\hline Causa & $\begin{array}{l}\text { Evento de perda de } \\
\text { transporte }\end{array}$ & $\begin{array}{c}\text { Atividade de transporte relacionada ao } \\
\text { evento }\end{array}$ & \multicolumn{2}{|c|}{$\begin{array}{c}N^{\circ} \text { de } \\
\text { eventos }\end{array}$} & $\begin{array}{c}\text { Tempo } \\
(\mathrm{h} / \mathrm{min} / \mathrm{s})\end{array}$ \\
\hline \multirow{8}{*}{ 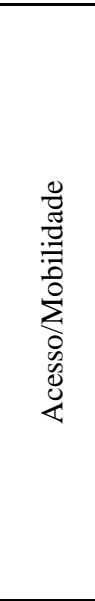 } & \multirow{8}{*}{$\begin{array}{l}\text { Presença de obstáculos } \\
\text { (trabalhadores, lama, } \\
\text { material mau estocado, } \\
\text { equipamentos, outros } \\
\text { estoques) no percurso do } \\
\text { transporte. }\end{array}$} & $\begin{array}{l}\text { Entrada do caminhão até próximo à } \\
\text { garagem }\end{array}$ & 2 & \multirow{8}{*}{35} & \multirow{8}{*}{ 01:23:00 } \\
\hline & & $\begin{array}{l}\text { Transporte dos pallets com sacos até a } \\
\text { garagem na carregadeira }\end{array}$ & 14 & & \\
\hline & & $\begin{array}{l}\text { Transporte via macaco hidráulico até dentro } \\
\text { da cremalheira }\end{array}$ & 2 & & \\
\hline & & $\begin{array}{l}\text { Transporte via macaco hidráulico até o } \\
\text { lugar onde será estocado }\end{array}$ & 4 & & \\
\hline & & $\begin{array}{l}\text { Transporte manual até perto da } \\
\text { argamassadeira }\end{array}$ & 4 & & \\
\hline & & $\begin{array}{l}\text { Transporte manual do estoque para o } \\
\text { carrinho de mão }\end{array}$ & 1 & & \\
\hline & & $\begin{array}{l}\text { Transporte via carrinho de mão até perto da } \\
\text { argamassadeira }\end{array}$ & 7 & & \\
\hline & & $\begin{array}{l}\text { Transporte via jerica até perto da } \\
\text { argamassadeira }\end{array}$ & 1 & & \\
\hline \multirow{4}{*}{ 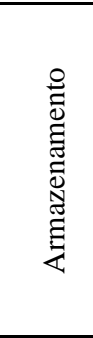 } & $\begin{array}{l}\text { Estoque de outros materiais } \\
\text { no local destinado à } \\
\text { argamassa }\end{array}$ & $\begin{array}{l}\text { Transporte dos pallets com sacos até à } \\
\text { garagem na carregadeira }\end{array}$ & 4 & \multirow{4}{*}{10} & \multirow{4}{*}{$00: 23: 37$} \\
\hline & \multirow{2}{*}{$\begin{array}{l}\text { Queda de sacos durante o } \\
\text { transporte, devido ao } \\
\text { armazenamento errado } \\
\text { sobre o pallet }\end{array}$} & $\begin{array}{l}\text { Transporte via macaco hidraulico até dentro } \\
\text { da cremalheira }\end{array}$ & 3 & & \\
\hline & & $\begin{array}{l}\text { Transporte via macaco hidráulico até o } \\
\text { lugar onde será estocado no andar }\end{array}$ & 2 & & \\
\hline & $\begin{array}{l}\text { Outros materiais } \\
\text { armazenados sobre os sacos }\end{array}$ & $\begin{array}{l}\text { Transporte manual do estoque para o } \\
\text { carrinho de mão }\end{array}$ & 1 & & \\
\hline \multirow{5}{*}{ 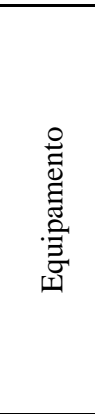 } & $\begin{array}{l}\text { Queda de sacos devido ao } \\
\text { fato de o pallets estar } \\
\text { quebrado }\end{array}$ & $\begin{array}{l}\text { Transporte dos pallets com sacos até à } \\
\text { garagem na carregadeira }\end{array}$ & 2 & \multirow{5}{*}{22} & \multirow{5}{*}{$04: 38: 23$} \\
\hline & \multirow{4}{*}{$\begin{array}{l}\text { Falta de equipamento } \\
\text { (carrinho de mão ou girica) } \\
\text { para realizar a atividade de } \\
\text { transporte }\end{array}$} & $\begin{array}{l}\text { Transporte manual até perto da } \\
\text { argamassadeira }\end{array}$ & 2 & & \\
\hline & & $\begin{array}{l}\text { Transporte manual do estoque para o } \\
\text { carrinho de mão }\end{array}$ & & & \\
\hline & & $\begin{array}{l}\text { Transporte via carrinho de mão até perto da } \\
\text { argamassadeira }\end{array}$ & 18 & & \\
\hline & & $\begin{array}{l}\text { Transporte manual do carrinho de mão para } \\
\text { o estoque perto da argamassadeira }\end{array}$ & & & \\
\hline 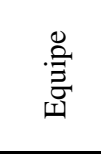 & $\begin{array}{l}\text { O pedreiro realiza a } \\
\text { atividade de transporte, } \\
\text { devido à ausência do } \\
\text { servente }\end{array}$ & Transporte manual até a argamassadeira & 1 & 1 & 00:03:00 \\
\hline \multirow{4}{*}{ 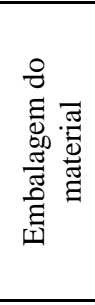 } & \multirow{4}{*}{$\begin{array}{l}\text { Saco rasgado dificultava o } \\
\text { transporte }\end{array}$} & $\begin{array}{l}\text { Transporte dos pallets com sacos até à } \\
\text { garagem na carregadeira }\end{array}$ & 3 & \multirow{4}{*}{13} & \multirow{4}{*}{$00: 15: 31$} \\
\hline & & $\begin{array}{l}\text { Transporte dos pallets com sacos até à } \\
\text { garagem na carregadeira }\end{array}$ & 1 & & \\
\hline & & $\begin{array}{l}\text { Transporte via macaco hidráulico até o } \\
\text { lugar onde será estocado }\end{array}$ & 2 & & \\
\hline & & $\begin{array}{l}\text { Transporte manual do estoque para o } \\
\text { carrinho de mão }\end{array}$ & 7 & & \\
\hline 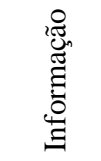 & $\begin{array}{l}\text { O motorista da carregadeira } \\
\text { armazena o pallet em local } \\
\text { errado }\end{array}$ & $\begin{array}{l}\text { Transporte dos pallets com sacos até à } \\
\text { garagem na carregadeira }\end{array}$ & 2 & 2 & 00:01:20 \\
\hline
\end{tabular}




\section{Estudo de caso 2}

\section{Características do processo e identificação dos fluxos físicos}

O empreendimento no Estudo 2 era constituído de casas em steel frame sobre fundação rasa do tipo radier. A sequência de execução depois do radier era:

(a) montagem dos frames;

(b) instalação do OSB (Oriented Strand Board) no térreo;

(c) montagem dos frames superiores e instalação do OSB superior;

(d) telhamento;

(e) instalações elétricas, hidráulicas, de lã de vidro e do OSB interno;

(f) concretagem das lajes;

(g) instalação de gesso acartonado, execução das juntas, instalação das placas cimentícias; e

(h) execução da fachada.

O transporte horizontal desde a entrada até o armazém era realizado em caminhão. $\mathrm{O}$ transporte horizontal desde o armazém até os estoque perto do radier era realizado pelo manipulador telescópico. O transporte horizontal e vertical desde os estoques perto do radier até o destino final era realizado de forma manual.

Durante o mapeamento dos processos estudados ficou clara a complexidade e os problemas de planejamento logístico no canteiro, principalmente quanto à estocagem e transporte. Buscou-se realizar um mapofluxograma que mostrasse o local onde as atividades eram realizadas, porém em função dos inúmeros estoques encontrados na área não foi possível realizar um único mapoxuflograma que refletisse a realidade do canteiro. Foi encontrado problema semelhante durante a realização dos diagramas de processos devido à contínua mudança na sequência, na forma de execução e no local onde as atividades eram realizadas. Dessa forma, devido à ausência de padronização mínima, o mapeamento ficou comprometido.

Apesar das dificuldades, buscou-se elaborar um diagrama de processo para cada um dos processos estudados que se aproximasse da sequência de execução das atividades de cada processo naquele momento, a fim de estimar os tipos de atividades, visando conduzir a coleta dos dados de amostragem do trabalho. Os resultados dos quatro processos estudados apresentavam uma relação entre as atividades semelhantes, de maneira que $10 \%$ das atividades eram de processamento, $40 \%$ de transporte, $20 \%$ de estoque e $30 \%$ de inspeção.

\section{Distribuição dos tempos dos trabalhadores}

A Tabela 2 apresenta os resultados da amostragem do trabalho. Do ponto de vista dos tempos produtivos, observa-se que a execução da fachada apresenta maior tempo produtivo $(66 \%$ das observações), seguido da realização do telhado (37\%), instalação da estrutura $(24 \%)$ e instalação de OSB (23\%). Um dos possíveis motivos de a instalação da estrutura e de OSB apresentar tempos produtivos tão reduzidos foi devido à grande quantidade de estoques intermediários encontrados no canteiro relativo a esses materiais, o que provocava a realização de mais atividades de transporte.

Tabela 2 - Resumo dos resultados da amostragem de trabalho no Estudo 2

\begin{tabular}{|c|c|c|c|c|c|c|}
\hline & \multirow[b]{2}{*}{ Tempo } & \multicolumn{5}{|c|}{ Equipe Direta } \\
\hline & & $\begin{array}{c}\text { Instalação } \\
\text { da } \\
\text { Estrutura }\end{array}$ & $\begin{array}{c}\text { Instalação } \\
\text { do OSB }\end{array}$ & $\begin{array}{r}\text { Realização } \\
\text { do Telhado }\end{array}$ & $\begin{array}{l}\text { Realização } \\
\text { da Fachada }\end{array}$ & $\begin{array}{c}\text { Geral do } \\
\text { LSF }\end{array}$ \\
\hline \multicolumn{2}{|c|}{ Tempos Produtivos } & $24 \%$ & $23 \%$ & $37 \%$ & $66 \%$ & $33 \%$ \\
\hline \multirow{3}{*}{$\begin{array}{l}\text { Tempos } \\
\text { Auxiliares }\end{array}$} & $\begin{array}{l}\text { Transportes } \\
\text { Inevitáveis } \\
\end{array}$ & $12 \%$ & $12 \%$ & $7 \%$ & $3 \%$ & $11 \%$ \\
\hline & $\begin{array}{l}\text { Transportes } \\
\text { Evitáveis }\end{array}$ & $17 \%$ & $4 \%$ & $4 \%$ & $1 \%$ & $6 \%$ \\
\hline & $\begin{array}{l}\text { Outras Atividades } \\
\text { Auxiliares }\end{array}$ & $23 \%$ & $25 \%$ & $11 \%$ & $13 \%$ & $22 \%$ \\
\hline \multirow{2}{*}{$\begin{array}{l}\text { Tempos } \\
\text { Improdu- } \\
\text { tivos }\end{array}$} & $\begin{array}{l}\text { Transportes } \\
\text { Desnecessários }\end{array}$ & $0 \%$ & $14 \%$ & $0 \%$ & $0 \%$ & $5 \%$ \\
\hline & $\begin{array}{l}\text { Outras Atividades } \\
\text { Improdutivas }\end{array}$ & $24 \%$ & $22 \%$ & $41 \%$ & $17 \%$ & $23 \%$ \\
\hline \multicolumn{2}{|c|}{ Total de Tempos } & $100 \%$ & $100 \%$ & $100 \%$ & $100 \%$ & $100 \%$ \\
\hline
\end{tabular}

256 Pérez, C. T.; Costa, D. B.; Gonçalves, J. P. 
Analisando todos os tempos de transporte, a amostragem do trabalhou revelou que o processo de instalação de OSB foi aquele que mais tempo utilizou para a realização de atividades de transporte ( $30 \%$ das observações), seguida de instalação da estrutura (29\%), realização do telhado $(11 \%)$ e realização da fachada $(4 \%)$. Considerando como perdas de tempos os transportes evitáveis e desnecessários, há $17 \%$ de perda de tempo para a instalação de estrutura, $18 \%$ de perda de tempo para a instalação de OSB, $4 \%$ de perda de tempo para a realização de telhado, e $1 \%$ para a realização de fachada.

\section{Identificação e quantificação das perdas}

Foram contabilizados 23 eventos de perdas por transporte ao longo do Estudo de Caso 2 durante 2 semanas (Quadro 8). Neste estudo não foi possível mensurar o tempo destinado à perda devido à recorrência dos eventos de perda, o que dificultava a determinação do começo da perda para a coleta do tempo. Os eventos de perdas por transporte foram classificados segundo suas causas. Dos eventos identificados 8 foram causados por falta de acesso/mobilidade, 9 foram decorrentes de problemas de armazenamento, 5 devido a equipamento, e 1 evento devido à equipe. Neste estudo nenhum dos eventos de perdas foi associado a embalagens dos materiais ou informação.

Quadro 8 - Eventos de perdas de transporte, sua incidência e tempo da perda no Estudo 2

\begin{tabular}{|c|c|c|c|c|c|}
\hline 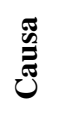 & $\begin{array}{l}\text { Evento de perda de } \\
\text { transporte }\end{array}$ & $\begin{array}{l}\text { Atividade de } \\
\text { transporte com } \\
\text { evento de perda }\end{array}$ & $\begin{array}{c}N^{o} \text { de } \\
\text { eventos }\end{array}$ & Consequência & $\begin{array}{l}\text { Associação } \\
\text { com outras } \\
\text { perdas }\end{array}$ \\
\hline \multirow{6}{*}{$\begin{array}{l}\frac{0}{0} \\
0 \\
0 \\
0 \\
0 \\
0 \\
0 \\
0 \\
0 \\
00 \\
0 \\
0\end{array}$} & \multirow{5}{*}{$\begin{array}{l}\text { Presença de } \\
\text { obstáculos (materiais, } \\
\text { entulho, buraco da } \\
\text { infraestrutura) nas } \\
\text { vias de acesso }\end{array}$} & \multirow{3}{*}{$\begin{array}{l}\text { Transporte } \\
\text { horizontal manual } \\
\text { da estrutura até o } \\
2^{\circ} \text { pavimento }\end{array}$} & \multirow{3}{*}{6} & $\begin{array}{l}\text { Necessidade de um novo } \\
\text { transporte (4) }\end{array}$ & Making-do (4) \\
\hline & & & & $\begin{array}{l}\text { Redução das condições de } \\
\text { segurança (4) }\end{array}$ & Retrabalho (1) \\
\hline & & & & Danificação do material (1) & $\begin{array}{c}\text { Trabalho } \\
\text { inacabado (1) }\end{array}$ \\
\hline & & \multirow{2}{*}{$\begin{array}{l}\text { Transporte } \\
\text { vertical manual da } \\
\text { estrutura até o } 2^{\circ} \\
\text { pavimento }\end{array}$} & \multirow[b]{2}{*}{1} & Problema ergonômico (1) & \multirow{2}{*}{$\begin{array}{c}\text { Trabalho } \\
\text { inacabado (1) }\end{array}$} \\
\hline & & & & $\begin{array}{l}\text { Necessidade de maior } \\
\text { percurso (1) }\end{array}$ & \\
\hline & $\begin{array}{l}\text { Porta menor que o } \\
\text { banco de trabalho }\end{array}$ & $\begin{array}{l}\text { Transporte de } \\
\text { banco para } \\
\text { instalação OSB }\end{array}$ & 1 & Danificação do material (1) & Making-do (1) \\
\hline \multirow{6}{*}{ 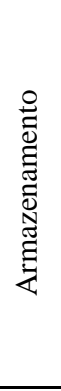 } & \multirow{4}{*}{$\begin{array}{l}\text { O motorista da } \\
\text { carregadeira tem que } \\
\text { descer para retirar } \\
\text { outros estoques de } \\
\text { forma manual }\end{array}$} & \multirow{2}{*}{$\begin{array}{l}\text { Transporte em } \\
\text { carregadeira até } \\
\text { área de estocagem }\end{array}$} & \multirow[b]{2}{*}{5} & Danificação do material (3) & Making-do (1) \\
\hline & & & & $\begin{array}{l}\text { Redução das condições de } \\
\text { segurança (1) }\end{array}$ & - \\
\hline & & \multirow{2}{*}{$\begin{array}{l}\text { Transporte em } \\
\text { carregadeira até o } \\
\text { radier }\end{array}$} & \multirow[t]{2}{*}{2} & \multirow{2}{*}{$\begin{array}{l}\text { Redução das condições de } \\
\text { segurança (2) }\end{array}$} & $\begin{array}{l}\text { Trabalho em } \\
\text { progresso (1) }\end{array}$ \\
\hline & & & & & Retrabalho (1) \\
\hline & \multirow{2}{*}{$\begin{array}{l}\text { Colaborador } \\
\text { improvisa estoque }\end{array}$} & \multirow{2}{*}{$\begin{array}{l}\text { Descarregamento } \\
\text { do OSB até a área } \\
\text { de estocagem }\end{array}$} & \multirow{2}{*}{2} & $\begin{array}{l}\text { Necessidade de um novo } \\
\text { transporte (2) }\end{array}$ & Making-do (1) \\
\hline & & & & $\begin{array}{l}\text { Necessidade de maior } \\
\text { percurso (1) }\end{array}$ & - \\
\hline \multirow{4}{*}{ 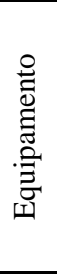 } & \multirow{2}{*}{$\begin{array}{l}\text { Falta de uma } \\
\text { carregadeira }\end{array}$} & \multirow{2}{*}{$\begin{array}{l}\text { Transporte } \\
\text { manual da } \\
\text { estrutura no térreo }\end{array}$} & \multirow[t]{2}{*}{2} & $\begin{array}{l}\text { Redução das condições de } \\
\text { segurança (2) }\end{array}$ & - \\
\hline & & & & Problema ergonômico (2) & - \\
\hline & \multirow{2}{*}{$\begin{array}{l}\text { Mangote hidráulico } \\
\text { com dificuldade nas } \\
\text { manobras }\end{array}$} & \multirow{2}{*}{$\begin{array}{l}\text { Transporte em } \\
\text { carregadeira até } \\
\text { área de estocagem }\end{array}$} & \multirow[b]{2}{*}{3} & Danificação do material (1) & Making-do (1) \\
\hline & & & & $\begin{array}{l}\text { Necessidade de um novo } \\
\text { transporte (2) }\end{array}$ & - \\
\hline$\stackrel{\mathscr{Z}}{\Xi}$ & $\begin{array}{l}\text { Falta de um dos } \\
\text { colaboradores no } \\
\text { andaime para ajudar } \\
\text { no transporte }\end{array}$ & $\begin{array}{l}\text { Transporte } \\
\text { vertical manual da } \\
\text { estrutura até o } 2^{\circ} \\
\text { pavimento }\end{array}$ & 1 & $\begin{array}{l}\text { Redução das condições de } \\
\text { segurança (1) }\end{array}$ & Making-do (1) \\
\hline
\end{tabular}


Figura 5 - Principais consequências das perdas por transporte

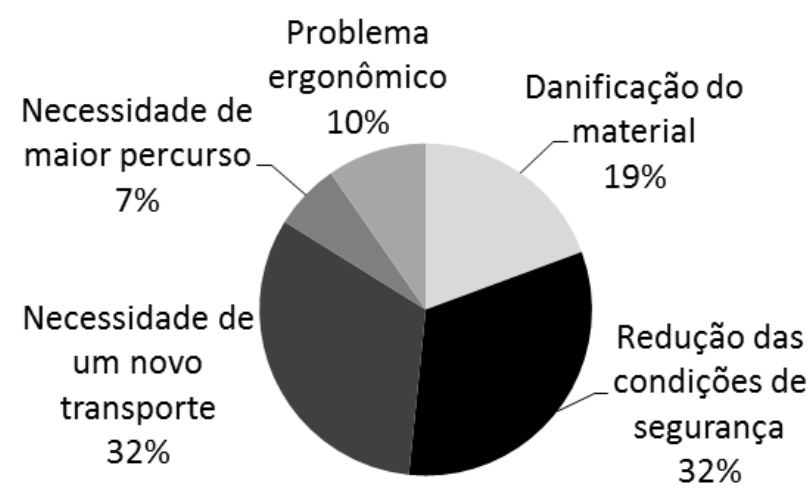

Figura 6 - Associação dos eventos de perdas por transporte com outras perdas

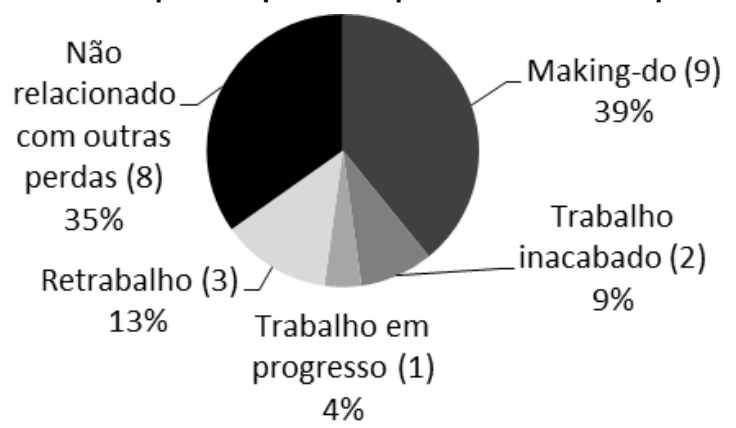

Como já mencionado, durante a identificação das consequências e associação com outras perdas, observou-se que cada evento de perda poderia estar relacionado com uma, duas ou três consequências simultaneamente, não significando que todos os eventos foram relacionados com três consequências, como mostra o número de incidência ocorrida em cada consequência e associação com outras perdas nas colunas 5 e 6 do Quadro 8.

Em termos quantitativos as principais consequências dos eventos de perdas foram a redução da segurança e a necessidade de um novo transporte, ambos com a incidência de 10 eventos (32\% do total) (Figura 5), enquanto making-do (9 eventos, 39\% do total) e retrabalhos (3 eventos, $13 \%$ do total) foram as principais outras perdas associadas (Figura 6).

\section{Discussão dos resultados}

\section{Ferramentas e indicadores para identificação e mensuração das perdas por transporte}

A partir do uso integrado de uma técnica e três ferramentas gerenciais já consolidadas na literatura foi possível o cálculo de 4 indicadores quantitativos, além de informações qualitativas das perdas de transporte, tais como suas principais causas e consequências, além dos locais com maior ocorrência de perdas por transporte.

A Tabela 3 apresenta o resultado dos dados coletados nos dois estudos de caso. A comparação dos resultados dos dois estudos deve ser realizada com cautela, levando em consideração as diferentes variáveis existentes, tais como os diferentes processos construtivos, tecnologias, configuração das equipes e forma de coleta. Os resultados quantitativos em ambos os estudos explicitaram a elevada quantidade de atividades de transportes e elevado tempo destinado a elas, comprovando que as atividades de transporte e suas perdas são atividades relevantes, que geraram impactos significativos nos fluxos físicos dos dois processos estudados. Além disso, os resultados qualitativos contribuem para a gestão das perdas, na medida em indicam de forma clara a existência de problemas no sistema de movimentação de materiais, apontando o local exato, a causa geradora da perda e as principais consequências, além de uma forte associação com as perdas de making-do.

Ao longo do estudo buscou-se coletar o indicador tempo perdido durante o evento de perda, que 
depende da identificação inicial do tempo regular ou ideal para realização da atividade de transporte, e a mensuração de tempos desnecessários utilizados para essa mesma tarefa, entendidos como perda. Apesar da realização da coleta no Estudo 1, essa medição se mostrou bastante complexa e subjetiva, principalmente no Estudo de Caso 2, que apresentava contínua mudança na forma de execução das atividades de transporte, seja no número de pessoas envolvidas, como no equipamento utilizado e no trajeto percorrido. Nesse sentido esse indicador depende de um sistema de produção estável e padronizado.

Observou-se que a combinação das ferramentas e técnicas adotadas contribuiu para a mensuração quantitativa e qualitativa das perdas por transporte, proporcionando benefícios do ponto de vista do entendimento sistêmico sobre as perdas por transporte, e que a adoção isolada desses indicadores e ferramentas não conseguiu explicitar essas informações importantes para a gestão e melhoria dos processos estudados.

\section{Classificações para caracterização das perdas por transporte}

Ao longo dos dois estudos realizados, a partir de intensa observação e coleta de dados em campo, com o suporte do referencial teórico, foi possível refinar e tornar mais claros conceitos essenciais utilizados no presente estudo, como "evento de perda de transporte", "causas das perdas por transporte" e "consequências das perdas por transporte", como apresentado no item Caracterização das perdas por transporte.

Tabela 3 - Ferramentas, técnicas, indicadores, caracterização e resultados obtidos

\begin{tabular}{|c|c|c|c|}
\hline $\begin{array}{l}\text { Ferramenta / técnica } \\
\text { utilizada }\end{array}$ & $\begin{array}{l}\text { Indicador / I nfor mações } \\
\text { qualitativas }\end{array}$ & Estudo de Caso 1 & Estudo de Caso 2 \\
\hline Diagrama de processo & $\begin{array}{l}\text { Percentual das atividades } \\
\text { de transporte }\end{array}$ & $46 \%$ & $40 \%$ \\
\hline \multirow[t]{3}{*}{$\begin{array}{l}\text { Amostragem de } \\
\text { trabalho }\end{array}$} & $\begin{array}{l}\text { Percentual do tempo } \\
\text { produtivo da equipe direta }\end{array}$ & $29 \%$ & $33 \%$ \\
\hline & $\begin{array}{l}\text { Percentual do tempo total } \\
\text { em atividades de } \\
\text { transporte }\end{array}$ & $34 \%$ & $23 \%$ \\
\hline & $\begin{array}{l}\text { Percentual do tempo } \\
\text { perdido em atividades de } \\
\text { transporte }\end{array}$ & $18 \%$ & $11 \%$ \\
\hline \multirow[t]{2}{*}{$\begin{array}{l}\text { Planilha com registro } \\
\text { fotográfico }\end{array}$} & $\begin{array}{l}\text { Causas das perdas por } \\
\text { transporte }\end{array}$ & $\begin{array}{l}\text { Acesso }(42 \%) \\
\text { Equipamentos } \\
(16 \%)\end{array}$ & $\begin{array}{l}\text { Acesso }(35 \%) \\
\text { Armazenamento } \\
(39 \%)\end{array}$ \\
\hline & $\begin{array}{l}\text { Consequências das perdas } \\
\text { por transporte }\end{array}$ & - & $\begin{array}{l}\text { Redução das } \\
\text { condições de } \\
\text { segurança }(32 \%) \\
\text { Necessidade de } \\
\text { novo transporte } \\
(32 \%)\end{array}$ \\
\hline $\begin{array}{l}\text { Planilha com registro } \\
\text { fotográfico e } \\
\text { Mapofluxograma }\end{array}$ & $\begin{array}{l}\text { Locais com maior } \\
\text { ocorrência de perdas por } \\
\text { transporte }\end{array}$ & Andar $(63 \%)$ & $\begin{array}{l}\text { Vias de acesso } \\
(52 \%)\end{array}$ \\
\hline
\end{tabular}


O evento de perda de transporte definido no presente trabalho está alinhado com o entendimento de Formoso et al. (1996) e de Bølviken, Rooke e Koskela (2014), que consideram que perdas ou ineficiências são decorrentes do uso de equipamentos, materiais, mão de obra e capital em quantidades superiores àquelas necessárias à produção da edificação.

Foi possível associar a classificação das causas nas perdas por transporte às causas de perdas por improvisação proposta por Sommer (2010), quais sejam, (falta de) acesso/mobilidade, ajuste de componentes, (falta de) adequação da área de trabalho, armazenamento, equipe/ferramentas, instalações provisórias e proteção. Das sete categorias propostas pelo referido autor, as categorias de acesso/mobilidade, armazenamento e equipe foram também entendidas como causas das perdas por transporte.

Além disso, grande parte das causas apresentadas neste estudo pode ser associada com algumas causas de perdas identificadas em outros trabalhos (ISHIKAWA, 1982; SOIBELMAN, 1993). A causa entendida neste estudo como "acesso/mobilidade" agruparia as perdas por más condições dos percursos, falta de espaço para o transporte e leiaute impróprio, identificadas por Soibelman (1993), podendo ser associada com a causa "método" (ISHIKAWA, 1982), por fazer referência à forma de realização das atividades. A perda identificada neste trabalho como "armazenamento" pode estar também associada à causa "método" (ISHIKAWA, 1982) e à falta de preparação para o recebimento dos materiais (SOIBELMAN, 1993). A perda entendida como "equipamento" foi denominada por Soibelman (1993) com o mesmo nome; e como "máquina" por Ishikawa (1982). A causa da perda "embalagem do material" pode ser associada à perda por "material defeituoso" (SOIBELMAN, 1993) e à causa "material" (ISHIKAWA, 1982). Segundo Ishikawa (1982), essa causa faz referência à forma como os materiais chegam, podendo estar danificados, errados ou perdidos. As causas denominadas neste trabalho de "equipe" e "informação" podem ambas ser enquadradas à causa "mão de obra" (ISHIKAWA, 1982), referente a grupos de montagem para realizar o transporte e à ausência de informação ou conhecimento ou desatenção de um colaborador no momento de realizar um transporte.

As consequências das perdas por transporte identificadas foram relacionadas à danificação do material, redução das condições de segurança, necessidade de maior percurso, problema ergonômico e necessidade de um novo transporte, esta última corroborando com Bølviken, Rooke e
Koskela (2014), que apontam como possível consequência das perdas nos fluxos a criação de um transporte desnecessário. Outras perdas, tais como perdas por making-do, retrabalho, trabalho inacabado e trabalho em progresso, também foram identificadas no Estudo 2, sendo identificadas ora como consequência, ora como causa dos eventos de perdas. Entretanto, existe a necessidade de investigação mais aprofundada em relação a esse tópico. Por fim, é importante destacar que a perda de tempo está associada a todos os eventos de perdas, porém é de difícil mensuração.

\section{Utilidade e facilidade de uso das ferramentas, indicadores e classificações}

Durante a avaliação preliminar do método os entrevistados consideraram as informações relativas a "principais causas das perdas de transporte" de grande utilidade para o controle e gestão da obra, além dos "locais com maior ocorrência de perdas por transporte" e do indicador "percentual do tempo perdido em transporte". O grau de concordância dos entrevistados referente à facilidade de uso apresentou resultados contraditórios entre os estudos. Os entrevistados do Estudo 1 consideravam as ferramentas e os indicadores moderadamente fáceis de ser aplicados devido ao maior envolvimento deles, em razão da realização de vários seminários e entrevistas não estruturadas ao longo do estudo. No entanto, os entrevistados do Estudo 2 consideravam relativamente difíceis devido à quantidade de tempo que precisam para sua implantação, assim como a quantidade de dados que precisam ser levantados e analisados. Esta dificuldade pode ter sido maior devido ao menor nível de envolvimento desses entrevistados no estudo. É importante destacar que há necessidade de implementação das ferramentas e indicadores por parte das obras para uma avaliação mais aprofundada da facilidade de uso e utilidade deles.

Do ponto de vista de relevância dos resultados, os envolvidos apresentaram interesse em relação aos dados apresentados, devido ao desconhecimento da grande parcela de tempo que as atividades de transporte ocupavam no processo.

\section{Conclusões e futuros trabalhos}

$\mathrm{O}$ presente artigo apresentou o processo para identificação, mensuração e caracterização das perdas por transporte nos fluxos físicos do processo construtivo de revestimento de argamassa com projeção mecânica e da tecnologia em Light Steel Frame, a partir do uso integrado de ferramentas, técnicas e indicadores gerenciais, bem como a definição de conceitos de perdas por 
transporte, suas causas e consequências. Ressaltase que a pesquisa limitou-se ao estudo das perdas de transporte e outras perdas identificadas, tais como making-do, trabalho inacabado, trabalho em progresso e retrabalho e espera, que foram associadas como causa ou consequência no presente estudo.

A contribuição prática do trabalho refere-se ao uso conjunto das ferramentas e técnicas e a proposição de quatro indicadores e informações qualitativas para identificação, mensuração e caracterização das perdas por transporte do ponto de vista de sua recorrência, tempos, causas e consequências. Esses indicadores contribuem para o aumento de informações para a gestão das perdas na construção, fornecendo um conjunto de dados, tanto qualitativo como quantitativo, o que dá suporte à identificação das perdas de transporte no processo construtivo estudado com impactos no sistema de produção visando a sua redução ou eliminação. É importante destacar também que o foco em processos construtivos ainda pouco empregados no Brasil foi uma decisão importante no presente estudo no sentido de gerar informações sobre perdas de transportes que possam subsidiar diretamente as melhorias desses processos ainda em desenvolvimento.

As ferramentas e os indicadores adotados na presente pesquisa mostram-se de fácil uso para os pesquisadores e a empresa, e de fácil entendimento para as pessoas envolvidas na obra, apesar de demandarem longo tempo para coleta das informações, em especial a coleta dos tempos perdidos nas atividades de transporte. A adoção dessas ferramentas e indicadores pelas obras depende de sua implantação pelos próprios gestores. Devido à intensiva coleta de dados, as empresas poderão julgar quais indicadores consideram de maior relevância e utilidade.

A segunda contribuição do presente trabalho, de caráter teórico, que contribui para o aumento do conhecimento da área de pesquisa de perdas na construção refere-se à explicitação e refinamento de um conjunto de conceitos e classificações que possibilitaram o entendimento das perdas por transporte de uma perspectiva sistêmica. A análise das causas e consequências pode contribuir para minimizar os tempos destinados às atividades de transporte e seus impactos no processo construtivo.

Como futuros estudos existe a necessidade de validação desse conjunto de ferramentas, indicadores e classificações em outros sistemas construtivos. Além disso, estudos podem ser conduzidos no sentido de identificar novas categorias de causas de perdas por transporte, consequências e impactos dessas perdas, bem como a associação das perdas por transportes com outras perdas na construção identificadas na literatura.

\section{Referências}

ALVES, T. C. L. Diretrizes Para Gestão dos Fluxos Físicos em Canteiros de Obra: proposta baseada em estudo de caso. Porto Alegre, 2000. Dissertação (Mestrado em Engenharia Civil) Núcleo Orientado para a Inovação da Edificação Programa de Pós-Graduação em Engenharia Civil, Universidade Federal do Rio Grande do Sul, Porto Alegre, 2000.

\section{BARNES, R. M. Estudo de Movimentos e}

Tempos: projeto e medida do trabalho. São Paulo: Edgar Blucher, 1977.

BØLVIKEN, T.; ROOKE, J.; KOSKELA L. The Wastes of Production in Construction: a TFV based taxonomy. In: ANNUAL CONFERENCE OF THE INTERNATIONAL GROUP FOR LEAN CONSTRUCTION, 22., Oslo, 2014. Proceedings... Oslo, 2014.

BOSSINK, B. A. G.; BROUWERS, H. J. H. Construction Waste: quantification and source evaluation, Journal of Construction Engineering Management, v. 122, n. 1, p. 55-60, 1996.

BULHÕES, I. R. Diretrizes Para Implementação de Fluxo Contínuo na Construção Civil: proposta baseada em dois estudos de caso. Campinas, 2009. Tese (Doutorado em Engenharia Ambiental Urbana) - Faculdade de Engenharia Civil, Arquitetura e Urbanismo, Universidade Estadual de Campinas, Campinas, 2009.

BURATI, J. L.; FARRINGTON, J. J.; LEDBETTER, W. B. Causes of Quality Deviations in Design and Construction. Journal of Construction Engineering Management, v. 118, n. 1, p. 34-39, 1992.

CHOI, S. et al. Waste Elimination of Mucking Process of a Petroleum Storage Tunnel through the Value Stream Analysis, In: ANNUAL

CONFERENCE OF THE INTERNATIONAL GROUP FOR LEAN CONSTRUCTION, 10., Manchester, 2002. Proceedings... Manchester, 2002.

CHOO, H., J.; TOMMELEIN, I. D. Space

Scheduling Using Flow Analysis In: CONFERENCE OF THE INTERNATIONAL GROUP FOR LEAN CONSTRUCTION, 7., Berkeley, 1999. Proceedings... Berkeley, 1999.

ENSHASSI, A. Materials control and waste on building sites, Building Research \& Information, v. 24 n. 1, p. 31-34, 1996. 
FORMOSO C. T. et al. Material Waste in Building industry: main causes and prevention. Journal of Construction Engineering and Management, v. 128, n. 4, p 316-325, 2002.

FORMOSO, C. T. et al. As Perdas na Cosntrução Civil: conceitos, classificações e seu papel na melhoria do setor. Porto Alegre, UFGRGS, 1996.

FORMOSO, C. T. et al. A Conceptual Framework for the Prescriptive Causal Analysis of Construction Waste. In: ANNUAL CONFERENCE OF THE INTERNATIONAL GROUP FOR LEAN CONSTRUCTION, 23., Perth, 2015. Proceedings... Perth, 2015.

\section{GHINATO, P. Lições Práticas Para a} Implantação da Produção Enxuta. Caxias do Sul: EDUCS, 2002.

HAN, S. et al. Identification and Quantification of Non-Value Adding Effort Due to Errors and Changes in Design and Construction Projects, Journal of Construction Engineering and Management, v. 1 n. 1, p. 291, 2011.

HEVNER A. et al. Design Science in Information Systems Research. Management Information Systems Quarterly, v. 28, n. 1, p. 75-105, 2004.

HWANG, B. G. et al. Measuring the Impact of Rework on Construction Cost Performance. Journal of Construction Engineering and Management, v. 135, n. 3, p. 187-198, 2009.

ISHIKAWA, K. Guide to Quality Control. $2^{\text {nd }}$. Tokyo: Asian Productivity Organization, 1982.

ISHIWATA, J. IE for the Shop Floor: productivity through process analysis. Portland: Productivity Press, 1991.

KALSAAS, B.T.; Measuring Waste and Workflow in Construction. In: ANNUAL CONFERENCE OF THE INTERNATIONAL GROUP FOR LEAN CONSTRUCTION, 21., Fortaleza, 2013. Proceedings... Fortaleza, 2013.

KALSAAS, B. T.; BØLVIKEN, T. Flow of Work in Construction: a conceptual discussion In: ANNUAL CONFEENCE OF THE INTERNATIONAL GROUP FOR LEAN CONSTRUCTION, 18., Haifa, 2010. Proceedings... Haifa, 2010.

KOSKELA, L. An Exploration Towards a Production Theory and its Application to Construction. Thesis (Ph.D) - Technical Research Centre of Finland, Espoo, 2000.

KOSKELA, L. Application of the New Production Philosophy to Construction. Standford: CIFE, 1992.
KOSKELA, L. Making-Do the Eighth Category of Waste, In: ANNUAL CONFEENCE OF THE INTERNATIONAL GROUP FOR LEAN CONSTRUCTION, 12., Elsinore, 2004, Proceedings... Elsinore, 2004.

KOSKELA, L.; BØLVIKEN, T.; ROOKE J. Which Are the Wastes in Construction? In: ANNUAL CONFEENCE OF THE INTERNATIONAL GROUP FOR LEAN CONSTRUCTION, 21., Fortaleza, 2013 Proceedings... Fortaleza, 2013.

KOSKELA, L.; SACKS, R.; ROOKE J. A Brief History of the Concepts of Waste in Production. In: ANNUAL CONFEENCE OF THE INTERNATIONAL GROUP FOR LEAN CONSTRUCTION, 20., San Diego, 2012. Proceedings... San Diego, 2012.

KOSKENVESA, A. et al. Waste and Labor Productivity in Production Planning. In: ANNUAL CONFEENCE OF THE INTERNATIONAL GROUP FOR LEAN CONSTRUCTION, 18., Haifa, 2008. Proceedings... Haifa, 2008.

LEDBETTER, W. B. Quality Performance on Successful Project. Journal of Construction Engineering Management, v. 120, n. 1, p. 34-46, 1994.

LOVE, P. Influence of Project Type and Procurement Method on Rework Costs in Building Construction Projects. Journal of Construction Engineering Management, v. 128, n. 1, p. 18-29, 2002.

LOVE, P; EDWARDS, D.J. Determinants of Rework in Building Construction Projects. Engineering, Construction and Architectural Management, v. 11, n. 4, p. 259-274, 2004.

MACOMBER, H.; HOWELL, G. 2004. The Two Great Wastes in Organizations. In: CONFERENCE OF THE INTERNATIONAL GROUP FOR LEAN CONSTRUCTION, 12 ., Helsingør, 2004. Proceedings... Helsingør, 2004.

MONDEN, Y. Toyota Production System: practical approach to production management. Industrial Engineering Management, p. 247, 1983.

NAHMENS, I.; IKUMA, L. H. Effects of Lean on Sustainability of Modular Homebuilding. Journal of Architectural Engineering, v. 1, n. 1, p. 25, 2011

NAHMENS, I.; MULLENS, M. A. Lean Homebuilding: lessons learned from a precast concrete panelizer. Journal of Architectural Engineering, v. 17, n. 4, p. 155, 2011. 
OHNO, T. O Sistema Toyota de Produção: além da produção em larga escala. Porto Alegre: Bookman, 1997.

OHNO, T. Toyota Production System. Cambridge: Productivity Press, 1988.

PEREZ, C. T.; COSTA, D. B.; GONÇALVES, J. P. Concepts and Methods For Measuring Flows and Associated Wastes. In: ANNUAL CONFEENCE OF THE INTERNATIONAL GROUP FOR LEAN CONSTRUCTION, 22 ., Oslo, 2014. Proceedings... Oslo, 2014.

ROTHER, M.; SHOOK, J. Aprendendo a Enxergar: mapeando o fluxo de valor para agregar valor e eliminar o desperdício. São Paulo: Lean Institute Brasil, 1999.

SANTOS, A.; FORMOSO, C. T.; HINKS, J. Method of Intervention on the Flow of Materials in Buildings Processes. In: ANNUAL CONFEENCE OF THE INTERNATIONAL GROUP FOR LEAN CONSTRUCTION, 4., Birmingham, 1996. Proceedings... Birmingham, 1996.

SENARATNE, S.; SEXTON, M. G. Role of Knowledge in Managing Construction Project Change. Engineering, Construction and Architectural Management, v. 16, n. 2, p. 186200, 2009.

SHINGO, S. A Revolution in Manufacturing: the SMED system. Portland: Productivity Press, 1985.

SKOYLES, E. R. Material Wastage, a Misuse of Resources. Batiment International Building Research and Practice, v. 4, n. 4, p. 232, 1976.
SOIBELMAN, L. As Perdas de Materiais na Construção de Edificações: sua incidência e controle. Porto Alegre, 1993. Dissertação (Mestrado em Engenharia Civil) - Programa de Pós-Graduação em Engenharia Civil, Universidade Federal do Rio Grande do Sul, Porto Alegre, 1993.

SOMMER, L. Contribuições Para Um Método de Identificação de Perdas por Improvisação em Canteiros de Obras. Porto Alegre, 2010. Dissertação (Mestrado em Engenharia Civil) Núcleo Orientado Para Inovação da Edificação, Programa de Pós-Graduação em engenharia civil, Universidade Federal do Rio Grande do sul, Porto Alegre, 2010.

THOMAS, R. H.; SANVIDO, M. A. A.; SANDER, S. R. Impact of Material management on productivity: a case study. Journal of Construction Engineering Management, Nova York, p. 370-384, 1989.

VIANA, D. D.; FORMOSO, C. T.; KALSAAS, B. T. Waste in Construction: a systematic literature review on empirical studies. In: CONFERENCE OF THE INTERNATIONAL GROUP FOR LEAN CONSTRUCTION, 20., San Diego, 2012. Proceedings... San Diego, 2012.

WOMACK, J. P.; JONES, D. T. Lean Thinking: banish waste and create wealth in your corporation. New York: Simon \& Schuster, 2004.

YU, H. et al. Development of Lean Model For House Construction Using Value Stream Mapping. Journal of Construction Engineering and Management, v. 135, n. 8, p. 782-790, 2009.

ZHAO, Z. Y. et al. Prediction System For Change Management in Construction Project. Journal of Construction Engineering Management, v. 136, n. 6, p. 659-669, 2010.

Cristina Toca Pérez

Mestrado em Engenharia Ambiental Urbana | Universidade Federal da Bahia | Rua Professor Aristides Novis, 2, Federação | Salvador - BA Brasil | CEP 40210-630 | Tel.: (071) 3283-9880 | E-mail: cristina.toca.perez@hotmail.es

\section{Dayana Bastos Costa}

Mestrado em Engenharia Ambiental Urbana, Departamento de Construção e Estruturas, Escola Politécnica | Universidade Federal da Bahia | Av. Aristides Novis, 2, Federação | Salvador - BA - Brasil | CEP 40210-630 | Tel.: (71) 3283-9731 | E-mail: dayanabcosta@gmail.com

Jardel Pereira Gonçalves

Mestrado em Engenharia Ambiental Urbana, Departamento de Construção e Estruturas, Escola Politécnica | Universidade Federal da Bahia | Tel.: (71) 3283-9725

E-mail: jardelpg@gmail.com

Revista Ambiente Construído

Associação Nacional de Tecnologia do Ambiente Construído

Av. Osvaldo Aranha, $99-3^{\circ}$ andar, Centro

Porto Alegre - RS - Brasil

CEP 90035-190

Telefone: +55 (51) 3308-4084

Fax: +55 (51) 3308-4054

www.seer.ufrgs.br/ambienteconstruido

E-mail: ambienteconstruido@ufrgs.br 